\title{
Revision of New World Loxocera (Diptera: Psilidae), with phylogenetic redefinition of Holarctic subgenera and species groups
}

\author{
Matthias BUCK and Stephen A. MARSHALL \\ Department of Environmental Biology, University of Guelph, Guelph, Ontario N1G 2W1, Canada; e-mail: mbuck@uoguelph.ca
}

Key words. Loxocera, Asiopsila, Psilidae, phylogeny, redefinition, subgenera, species groups, key, new species, new synonymy, New World, egg

\begin{abstract}
The New World species of Loxocera Meigen are revised including two new species, L. (Imantimyia) ignyodactyla Buck sp. n. from Costa Rica (first record of the genus from the Neotropical region) and L. (Imantimyia) ojibwayensis Buck sp. n. from Ontario, Canada. Loxocera californica Capelle is synonymized with $L$. collaris Loew and lectotypes are designated for $L$. pleuritica Loew and $L$. cylindrica var. obsoleta Johnson (both synonyms of $L$. cylindrica Say). The New World species are diagnosed and a key to species is provided. The male and female terminalia of Loxocera are described in detail for the first time, and their functional morphology is discussed. Eggs of most species are described and a key to the known eggs of Loxocera is provided. A phylogenetic framework for the Holarctic subgenera and species groups of Loxocera is developed based on morphological characters of the adult flies. The Old World subgenus Platystyla Macquart is synonymized with Loxocera s. str., and Imantimyia Frey is reinstated as a valid subgenus including all Holarctic species previously placed in Loxocera s. str. except the L. aristata species group. This leads to the following new subgeneric combinations: $L$. (L.) malaisei Frey comb. n., L. (L.) matsumurai Iwasa comb. n., L. (L.) monstrata Iwasa, comb. n., and L. (L.) omei Shatalkin comb. n. The species groups of Imantimyia are redefined, i.e. the L. achaeta-group (7 spp.), the L. fulviventris-group (4 spp.), and the L. albiseta-group (1 sp.). The Oriental subgenus Asiopsila Shatalkin is referred to Psila Meigen s. 1. as a subgenus based on characters of the egg, resulting in fourteen new generic combinations: Psila (Asiopsila) brevibuccata (Shatalkin) comb. n., P. (A.) burmanica (Frey) comb. n., P. (A.) decorata (de Meijere) comb. n., P. (A.) derivata (Shatalkin) comb. n., P. (A.) formosana (Hennig) comb. n., P. (A.) freidbergi (Shatalkin) comb. n., $P$. (A.) humeralis (de Meijere) comb. n., P. (A.) kambaitensis (Frey) comb. n., P. (A.) limpida (Shatalkin) comb. n., P. (A.) maculipennis (Hendel) comb. n., $P$. (A.) michelseni (Shatalkin) comb. n., P. (A.) pleuralis (Frey) comb. n., P. (A.) primigena (Shatalkin) comb. n., and $P$. (A.) vittipleura (Shatalkin) comb. n.
\end{abstract}

\section{INTRODUCTION}

The Psilinae genus Loxocera Meigen, 1803 currently includes 61 described species, most of which (56 spp.) occur in the Old World. Previous authors have divided the genus into four subgenera: the Nearctic and Old World Loxocera s. str. (38 spp.), the Palaearctic and Oriental Platystyla Macquart, 1835 (5 spp.), the east Palaearctic Tropeopsila Shatalkin, 1983 (2 spp.), and the Oriental Asiopsila Shatalkin, 1998 (14 spp.) (2 Oriental species are unplaced to subgenus and might not belong in Loxocera, see Shatalkin, 1998). The subgenus Asiopsila was erected for a distinct clade of Oriental species (Shatalkin, 1998), but Shatalkin (1. c.) expressed doubts about its placement in Loxocera s. 1. An additional subgenus, Imantimyia, was proposed by Frey (1925) for species related to the European L. albiseta (Schrank, 1803) but the subgenus was considered a synonym of Loxocera $\mathrm{s}$. str. by subsequent authors. Three species currently placed in the Afrotropical genus Loxocerosoma Verbeke, 1968, probably belong in Loxocera.

The Nearctic species of Loxocera were first revised by Johnson (1920), who recognised three species (L. cylindrica Say, 1823 (Fig. 1), L. collaris Loew, 1869 and L. fumipennis Coquillett, 1901) and four colour varieties of L. cylindrica. Shortly thereafter Melander (1920) added a new species from the western US (L. microps). The most recent taxonomic paper on New World Loxocera is
Capelle's (1953) revision, in which one more species was described (L. californica). We here redefine Loxocera, review its subgenera and species groups, and revise the New World species of the genus with the addition of a first Neotropical Loxocera and a new northeastern Nearctic species. Descriptions of the eggs of New World species and of exemplars of most Old World species groups/subgenera are also provided, including a key to all known eggs of Loxocera s. 1.

\section{MATERIAL AND METHODS}

\section{Preparation methods}

Male and female abdomens were cleared in hot $10 \% \mathrm{KOH}$, neutralized in glacial acetic acid and stored in glycerine. All eggs described in this paper were obtained by dissection from gravid females (museum specimens). Females usually contain mature eggs, providing an easily accessible additional character set for taxonomic and/or phylogenetic analyses. The eggs of Psilidae offer useful specific characters as well as characters of great phylogenetic value at the generic level. We therefore suggest that it should be standard procedure to include descriptions of eggs when describing new taxa in this family.

\section{Photography}

Photographs of museum specimens (Figs 3-6, 17-20) were taken with a Microptics Digital Lab XLT imaging system using a Canon EOS 1 Ds camera and Microptics ML-1000 flash fibre optic illumination system. Each image was assembled from a 


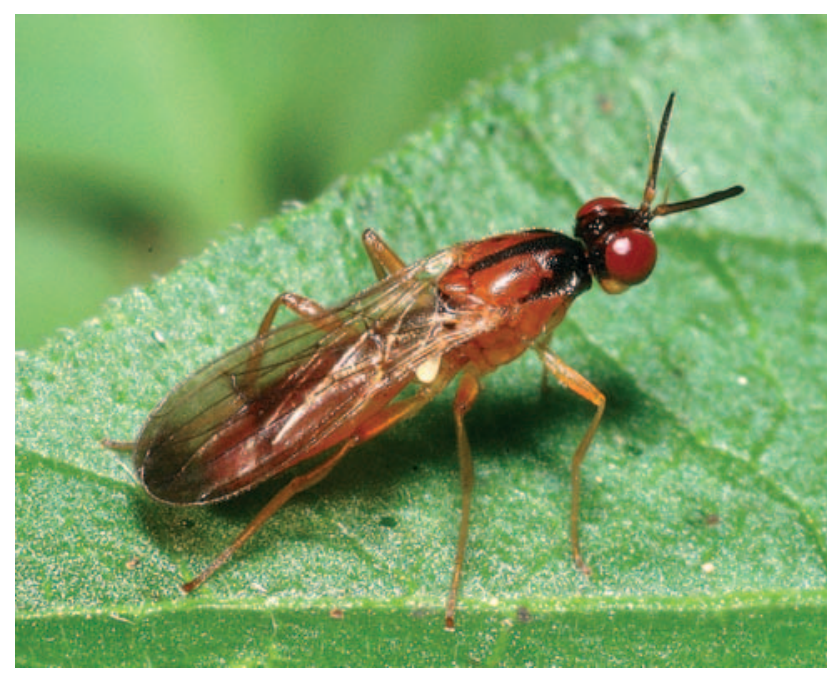

Fig. 1. Loxocera (Imantimyia) cylindrica male perched on leaf (Canada, Ontario).

series of photographs (with different focal planes) using the computer freeware CombineZ, version 4.6 (Hadley, 2004).

\section{Terminology}

The morphological terminology follows McAlpine (1981) except for certain terms pertaining to the phallic complex, which follow Andersson (1977):

As in most Schizophora the psilid hypandrium consists of a more or less developed, anterior, horizontal, transverse, often plate-like portion ("hypandrial plate") and a pair of posterior arms ("hypandrial arms") (e.g., Fig. 57). Rarely, the hypandrial arms are fused posteriorly forming a hypandrial bridge (Fig. 7: $\mathrm{hb}$ ). The hypandrial arms have been erroneously termed "surstylar apodemes", "gonopods" (Shatalkin, 1986, 2002; Steyskal, 1987) or "processi longi" [= subepandrial sclerite] (Wang, 1988). We agree with Hennig (1941) in considering these structures of hypandrial origin. The phallapodeme [= aedeagal apodeme (p.p.) of McAlpine, 1981] is a laterally (rarely dorsoventrally) flattened, cuticular ingrowth that serves for the attachment of muscles (e.g., Fig. 21: pa). It is supported ventrally by the phallapodemic sclerite $[=$ aedeagal guide + aedeagal apodeme (p.p.) of McAlpine, 1. c.], whose anterior portion forms a broad, flat or longitudinally folded plate (e.g., Figs 21, 22: ps). The narrower posterior portion of the phallapodemic sclerite bifurcates into two arms ("phallapodemic arms") (e.g. Fig. 34: psa), which embrace the base of the phallus (= aedeagus of McAlpine, 1981). Along its margins the phallapodemic sclerite is membranously connected or partially fused to the hypandrium. A special feature of Psilidae is the "phallic pouch" (e.g., Fig. 57: pp), which is delimited ventrally by the hypandrial plate and dorsally by the anterior part of the phallapodemic sclerite.

\section{Acronyms of depositories}

CASC - California Academy of Sciences, San Francisco, California, USA; CNCI - Canadian National Collection of Insects, Ottawa, Ontario, Canada; DEBU - Department of Environmental Biology, University of Guelph, Guelph, Ontario, Canada; INBC - Instituto Nacional de Biodiversidad, Santo Domingo de Heredia, Costa Rica; MCZC - Museum of Comparative Zoology, Harvard University, Cambridge, Massachusetts, USA; ROME - Royal Ontario Museum, Toronto, Ontario, Canada; SEMC - Snow Entomological Museum, University of Kansas, Lawrence, Kansas, USA; USNM - United States

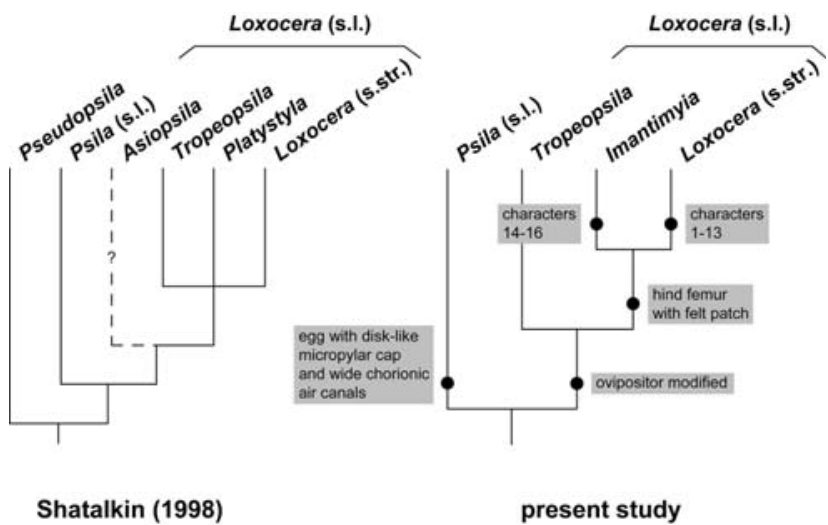

Fig. 2. Phylogeny of the subfamily Psilinae. Explanations: Black circles represent apomorphic character states (for explanation of characters 1-16 see text: Groundplan of subgenus Loxocera). In the present study we include Pseudopsila and Asiopsila in Psila s. 1., synonymize Platystyla with Loxocera s. str., and reinstate Imantimyia as a valid subgenus of Loxocera.

National Museum, Washington, D.C., USA; ZSMC - Zoologische Staatssammlung, München, Germany.

\section{Genus Loxocera Meigen, 1803}

Loxocera Meigen, 1803: 275. Type species: Musca aristata Panzer, 1801: 24 (by monotypy).

Type species of the genus. Under the original description of Loxocera Meigen (1803: 276) somewhat ambiguously mentions a single species: "Mulio ichneumoneus Fabr. s. [= synonym] Musca aristata Panzer". "Mulio ichneumoneus Fabr." in fact refers to Musca ichneumonea Linnaeus, 1761, which is usually cited as the type species of Loxocera (e.g., Frey, 1925; Hennig, 1941; Shewell, 1965; Cogan, 1977). Unfortunately, the identity of this species is doubtful, and the name possibly refers to a species of Syrphidae (Soós, 1984: 35). Traditionally, Musca ichneumonea has been considered a senior synonym of either Loxocera aristata (Panzer, 1801) (e.g., Frey, 1925; Hennig, 1941) or L. albiseta (Schrank, 1803) (e.g., Becker, 1905). Apparently, Meigen (1803) himself felt the need to clarify the concept of Musca ichneumonea by giving the synonymy with Musca aristata (in his whole 1803 work this is the only instance, where a synonymy is mentioned). Due to the fact that the identity of Musca ichneumonea cannot be ascertained, and Meigen (1803) intended to refer but to a single species, we are following Soós (1984) in considering Musca aristata the type species of Loxocera.

Sister group. The most recent discussion of the phylogenetic relationships of Loxocera was presented by Shatalkin (1998). In Fig. 2 his written description of Psilinae phylogeny is translated into a cladogram and compared to our own phylogenetic hypothesis (see below). Both hypotheses agree in regarding Psila Meigen, 1803 s. 1. as the sister group of Loxocera s. 1. (for the monophyly of Psila s. 1. see Buck \& Marshall, 2006). However, Shatalkin (1998) excluded Pseudopsila Johnson, 1920 from Psila s. 1., leading to a very different groundplan for Psila s. 1. and the Psilinae, and resulting in 

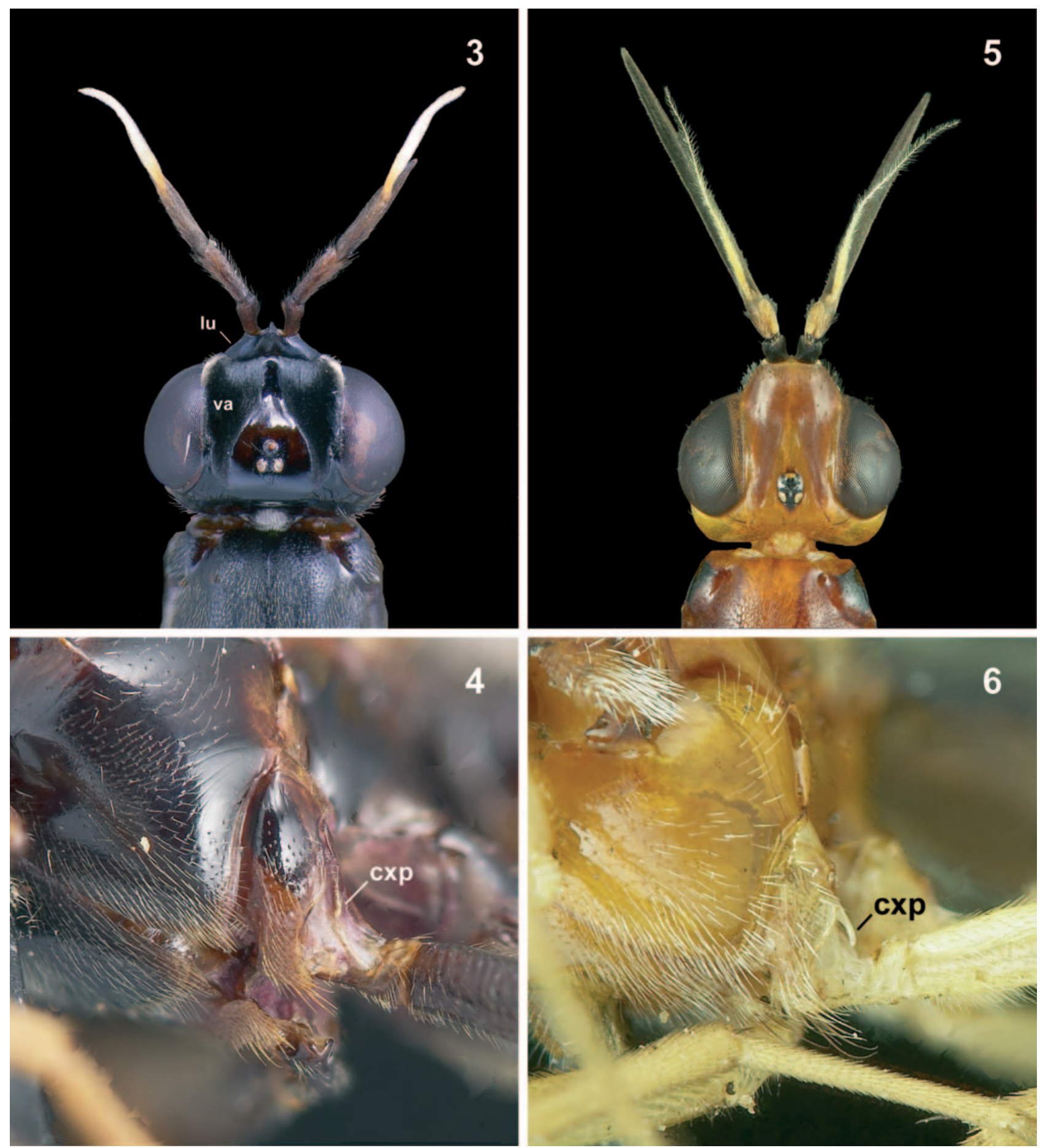

Figs 3-6. External characters of Loxocera s. str. and Loxocera (Imantimyia). L. (L.) hoffmannseggi: 3 - female, head, dorsal view (Germany, Bayern); 4 - mid coxa, anteroventral view (Germany, Baden-Württemberg). L. (I.) ignyodactyla sp. n.: 5 - female, head, dorsal view (paratype; Costa Rica, Puntarenas). L. (I.) albiseta: 6 - mid coxa, anteroventral view (Germany, Nordrhein-Westfalen). cxp - mid coxal prong, lu - lunule, va - velvety area of frons.

different polarities for certain characters of phylogenetic importance within Loxocera. In a separate paper (Buck \& Marshall, 2006) we clarify the identity of Pseudopsila, confirm its placement in Psila s. 1. and redefine Psila s. 1. based on egg morphology. Characters used in the phylogenetic analysis of subgenera and species groups of Loxocera are polarized through outgroup comparison with
Psila s. 1. and Chyliza Fallén, 1820 (the putative sister group of Psilinae, see Shatalkin, 2002).

Monophyly. Originally, the genus Loxocera included only species possessing a preapical patch of dense, feltlike microtomentum below the hind femur (Fig. 56: fp). The felt patch has obviously evolved in the stem species of this group because no similar structure is found in any related group of flies. Unlike Shatalkin (1998), who inter- 

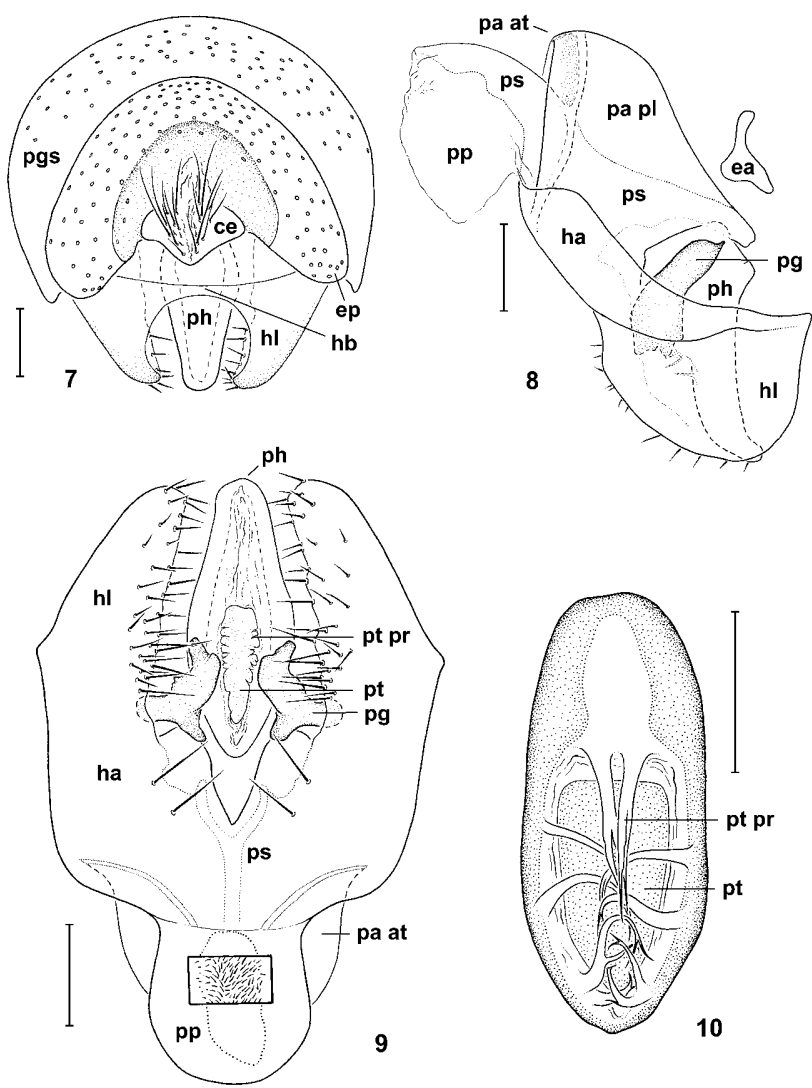

Figs 7-10. Male genitalia of Loxocera s. str. L. aristata (Sweden, Värmland): 7 - pregenital sclerite and hypopygium, caudal view; 8 - hypandrium and associated structures, left lateral view; 9 - ditto, ventral view, rectangular window showing microtrichose inner surface of phallic pouch. L. hoffmannseggi (Germany, Baden-Württemberg): 10 - phallus, ventral view. Scale $0.1 \mathrm{~mm}$. ce - cercus, ea - ejaculatory apodeme, ep - epandrium, ha - hypandrial arm, hb - hypandrial bridge, hl - hypandrial lobe, pa at - phallapodeme, anterior transverse portion, pa $\mathrm{pl}$ - phallapodeme, posterior longitudinal portion, pg - postgonite, pgs - pregenital sclerite, $\mathrm{ph}$ - phallus, pp - phallic pouch, ps - phallapodemic sclerite, $\mathrm{pt}$ - phallotrema, pt pr - cuticular processes around phallotrema.

preted this character as "probably plesiomorphic" without providing any explanation, we consider it a defining character of Loxocera. No further apomorphies for this clade were found. Loxocera in this original sense has been divided into two subgenera (treated as genera by Frey, 1925): Platystyla and Loxocera s. str. For reasons explained below, the subgeneric limits are redefined here and Imantimyia (previously treated as a synonym of Loxocera s. str.) is recognised as the sister group of Loxocera s. str.

Shatalkin (1989) added Tropeopsila as a third subgenus to Loxocera, after previously describing it as a separate genus (Shatalkin, 1983). Tropeopsila shares with Loxocera s. str. and Imantimyia the modified, coriaceous, laterally compressed ovipositor and moderately elongate first flagellomere but lacks the femoral patch of felt-like microtomentum. The modified ovipositor is a putative synapomorphy for Tropeopsila + (Imantimyia + Loxocera s. str.). However, Psilosoma Zetterstedt, 1860, which is currently considered a subgenus of Psila (e.g., Iwasa, 1998), shows a similar ovipositor morphology, and the relationships of this group require further study. Traditionally, elongate antennae have been considered an autapomorphy of Loxocera, as well, but this character also occurs in several subgenera of Psila, i.e. Freyopsila Shatalkin, 1986 (see Shatalkin, 1998), Asiopsila (see below), Psila s. str. and Xenopsila Buck, 2006 (Buck \& Marshall, 2006), and it is possible that elongate antennae are part of the ground plan of the Psilinae. Without access to material of Tropeopsila we are unable to further clarify its relationships.

Several Oriental species, which were added to Loxocera s. str. by various earlier authors, share with Tropeopsila, Imantimyia and Loxocera s. str. the elongate first flagellomere but lack all other apomorphic characters that define Loxocera. Shatalkin (1998) demonstrated that these species from a monophyletic group which is characterized by three unique autapomorphies: a pale microtomentose patch on the katepisternum, small alula, and the lack of postgonites. Shatalkin (1998: 92) erected a new subgenus Asiopsila for this group (type species: Loxocera maculipennis Hendel, 1913), and expressed strong reservations about its placement in Loxocera s. 1. Based on new evidence from egg morphology we are now convinced that Asiopsila is part of Psila s. 1. and does not belong in Loxocera. Asiopsila shares with other subgenera of Psila the highly characteristic, disk-like, micropylar cap and wide, reticulated, chorionic air canals (see below in section on eggs), which we consider putative autapomorphies of Psila s. 1. (Buck \& Marshall, 2006). We therefore transfer Asiopsila to Psila s. 1. as a subgenus, proposing the following fourteen new generic combinations: P. (A.) brevibuccata (Shatalkin, 1998) comb. n., P. (A.) burmanica (Frey, 1955) comb. n., $P$. (A.) decorata (de Meijere, 1914) comb. n., P. (A.) derivata (Shatalkin, 1998) comb. n., P. (A.) formosana (Hennig, 1940) comb. n., P. (A.) freidbergi (Shatalkin, 1998) comb. n., P. (A.) humeralis (de Meijere, 1916) comb. n., P. (A.) kambaitensis (Frey, 1955) comb. n., P. (A.) limpida (Shatalkin, 1998) comb. n., P. (A.) maculipennis (Hendel, 1913) comb. n., P. (A.) michelseni (Shatalkin, 1998) comb. n., P. (A.) pleuralis (Frey, 1928) comb. n., P. (A.) primigena (Shatalkin, 1998) comb. n., P. (A.) vittipleura (Shatalkin, 1998) comb. $\mathrm{n}$.

Subgeneric classification. The subgenus Loxocera s. str. as defined by previous authors is paraphyletic with regard to Platystyla. A small group of species in Loxocera s. str., which includes the type species of the genus, forms a well-defined monophyletic group with the species of Platystyla. It is therefore necessary to synonymize the latter with the former. The remainder of the species previously placed in Loxocera s. str. also form a monophyletic group, and include the type species of Imantimyia, a subgeneric name that has been considered a synonym of Loxocera s. str. by all workers except its original author Frey (1925). Imantimyia is reinstated here as a subgenus, including all the species formerly placed in Loxocera $\mathrm{s}$. 
str. except the L. aristata-group, which remains in Loxocera s. str.

Diagnosis. Loxocera s. 1 . in the present redefined sense is diagnosed as follows: face more or less receding (as typical for the subfamily) (Figs 17-20); first flagellomere long, at least 5.5× as long as broad (high) (Figs 17-20), if shorter (most Loxocera s. str.) then arista removed from base of first flagellomere (Fig. 3), inserted in distal half or slightly before middle of flagellomere; posterior half of anepisternum with a patch of dense, downcurved hair ventrally (Fig. 19: hp) (poorly developed in some species); laterotergite slightly convex (as typical for the subfamily), not protruding; hind femur usually with preapical patch of very dense, felt-like microtomentum on lower surface; female terminalia laterally compressed and coriaceous.

\section{Key to the subgenera of Loxocera}

1 Ventral surface of hind femur without patch of dense microtomentum (east Palaearctic).............. Tropeopsila

- Ventral surface of hind femur with a patch of dense, felt-like microtomentum in distal half. . . . . . . . . . . . 2

2 Frontal vitta largely velvety and dull, desclerotized (Fig. 3) Lunule (Fig. 3: lu) sclerotized and broadly exposed between antennal base and anterior margin of frons (rarely withdrawn in dry specimens). Alula bare except margin. Male pregenital sclerite large and exposed, setulose (Fig. 7: pgs). Female cerci contiguous with tergite 10 but separate (Fig. 11) (Palaearctic, Oriental). ........... Loxocera s. str. Frontal vitta sclerotized (Fig. 5), at least subshining, never velvety. Lunule usually hidden (Fig. 5), at most very narrowly exposed between antennal base and anterior margin of frons. Alula microtrichose. Male pregenital sclerite small and withdrawn, bare. Female cerci completely fused to tergite 10, forming one continuous sclerite (e.g., Fig. 12) (widespread) .................... Imantimyia

\section{Morphology and function of male and female terminalia}

The male and female terminalia of Loxocera have never been described in detail, although Capelle (1953) illustrated postgonites of the Nearctic species, Griffiths (1972) provided a brief description of the male genitalia of Psilidae (including brief references to L. cylindrica), and Shatalkin $(1989,1998)$ discussed certain features of the male genitalia providing simple illustrations for most subgenera. Even recent species descriptions include little if any information on the male and female genitalia (Iwasa, 1992, 1993, 1996; Shatalkin, 1998). As the following phylogenetic reassessment of the subgenera of Loxocera relies heavily on genitalic characters it is necessary to provide a detailed generic description.

The following description of the male and female terminalia and their function apply only to the subgenera Loxocera s. str. and Imantimyia (Tropeopsila was not available for examination). Notes on Loxocera s. str. are based on the European species L. hoffmannseggi Meigen, 1826, L. aristata and L. maculata Rondani, 1876; notes on Imantimyia are mainly based on the New World species and on the European L. albiseta.

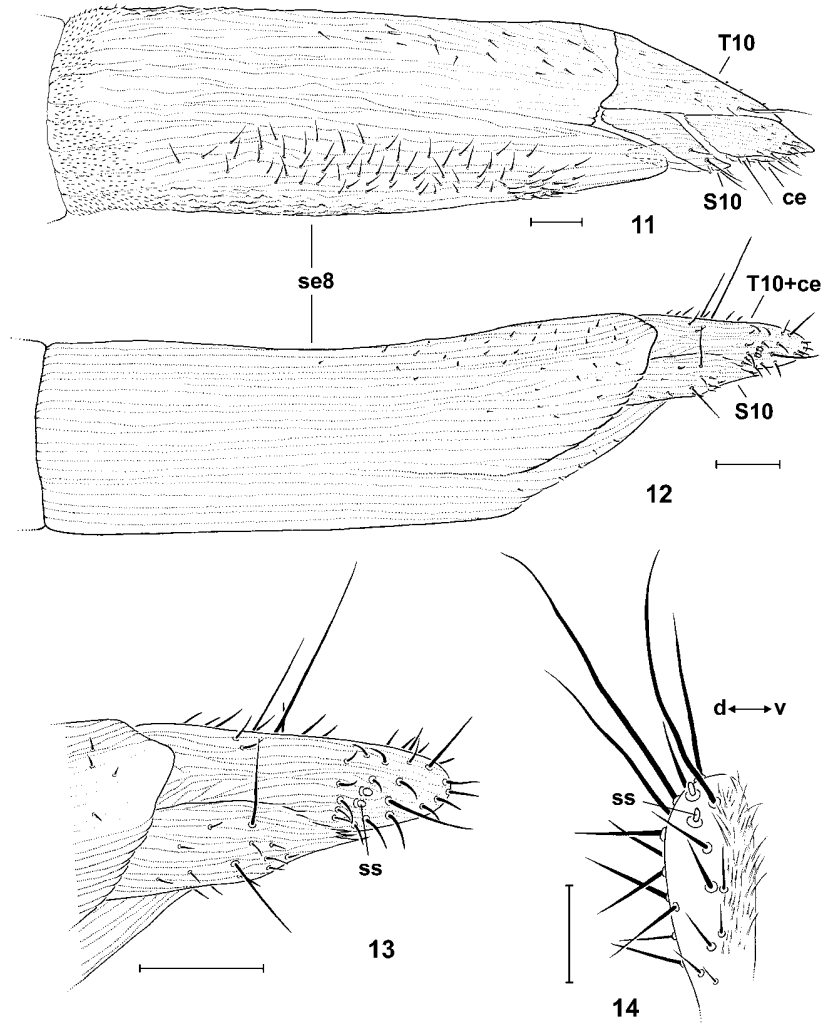

Figs 11-14. Female genitalia of Loxocera s. str., L. (Imantimyia) and Chyliza. Loxocera (L.) aristata (Sweden, Värmland): 11 - ovipositor from segment 8 onward, lateral view. Loxocera (Imantimyia) albiseta (England, Devon): 12 ovipositor from segment 8 onward, lateral view; 13 - apex of ovipositor, lateral view. Chyliza apicalis (Canada, Ontario): 14 - left cercus, lateral view. Scale $0.1 \mathrm{~mm}$ (ovipositors) and 0.05 $\mathrm{mm}$ (cercus). ce - cercus, $\mathrm{d}-$ dorsal, se 8 - segment 8 , ss - peglike sensilla, S10 - sternite $10, \mathrm{~T} 10$ - tergite $10, \mathrm{v}$ - ventral.

\section{Male terminalia}

Morphology. Abdomen with symmetrical pregenital sclerite between tergite 6 and epandrium. This sclerite is probably homologous to tergite 7 but possibly incorporates fused remnants of sternite 8 (homology with tergite 7 suggested by location of spiracles 7 at ventrolateral margins of pregenital sclerite). Pregenital sclerite of Imantimyia bare and short (illustrated by Griffiths, 1972: Fig. 48), often weakened or interrupted medially, lateral portions folded inward and thus not visible in lateral view; pregenital sclerite of Loxocera s. str. large (distinctly larger than epandrium) (Fig. 7: pgs), exposed and extensively setulose, fused to epandrium along posterior margin. Sternite 7 absent but some species (L. (I.) albiseta and some African species, see Verbeke, 1952) possess a very short, transverse, bare sclerite behind sternite 6 , which might be homologous to sternite 7. Spiracles 7 symmetrically placed behind spiracles 6. Epandrium forming a simple arch. Surstyli absent. Subepandrial sclerite absent in Loxocera s. str., present but often weakly sclerotized in Imantimyia (not absent as stated by Griffiths, 1972), medially divided into two broadly separated halves; each half with a vertical ventral portion (Fig. 


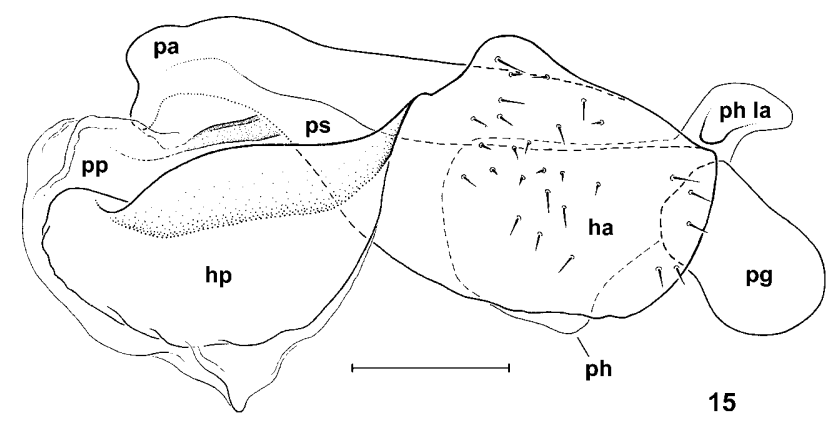

Fig. 15. Hypandrium and associated structures of Loxocera (Imantimyia) albiseta (Austria, Oberösterreich), left lateral view. Scale $0.1 \mathrm{~mm}$. ha - hypandrial arm, hp - hypandrial plate, pa - phallapodeme, pg - postgonite, $\mathrm{ph}$ - phallus, ph la - phallus, lateral arm, pp - phallic pouch, ps - phallapodemic sclerite.

45: se vp), and a horizontal dorsal portion (Fig. 46: se dp). Hypopygium in Imantimyia with a cavity extending anteriorly below cerci (Fig. 45), dorsally and laterally delimited by subepandrial sclerite, ventrally delimited by hypandrial/phallic complex; cavity absent in Loxocera s. str. (Fig. 7) and hypopygium closed by a vertical membrane connecting base of cerci with hypandrial bridge. Hypandrial plate present in Imantimyia but short and often weakly sclerotized, divided into two halves in $L$. albiseta, completely desclerotized in Loxocera s. str. (Figs 8, 9). Hypandrial arms in Imantimyia forming more or less extensive vertical plates (e.g., Fig. 33: hy), connected to phallapodemic sclerite through membranous area; in Loxocera s. str. hypandrial arms fused to phallapodemic sclerite anteriorly (Fig. 9: ha, ps); posteriorly produced into large, convex, setulose lobes (Figs 7, 8: hl), projecting below epandrium like surstyli. Hypandrial bridge present and robust in Loxocera s. str. (Fig. 7: hb); absent in Imantimyia. Phallic pouch variable in size and degree of sclerotization, laterally compressed and sometimes with denticulate surface structure in Nearctic Imantimyia (Figs 44, 47); phallic pouch very large and mostly to completely membranous ventrally in Loxocera s. str. (Figs 8, 9: pp). Phallapodeme of Imantimyia laterally compressed and of variable size, completely fused to phallapodemic sclerite (Fig. 21: pa), rarely free anteriorly (Fig. 43: pa); phallapodeme of Loxocera s. str. anteriorly divided into two perpendicular arms (i.e., T-shaped, Figs 8, 9: pa at), which form a transverse crest on phallapodemic sclerite; posterior longitudinal portion well developed (Fig. 8: pa pl) or more or less reduced. Phallapodemic sclerite bearing at least a few setulae, longitudinally folded or arched, forming a V- or U-shaped roof over genital cavity, posteriorly bifurcate, bifurcate portion sometimes much longer than anterior undivided portion. Postgonites directed posteriorly (Fig. 15), ventrally (Fig. 8), laterally (e.g., Fig. 34) or (in African species, teste Shatalkin, 1998) anteriorly, articulated more or less apically on phallapodemic arms (e.g., Fig. 34) or near middle (e.g., Fig. 58), articulated laterally to hypandrial arms. Phallus simple and symmetrical, not divided into basi- and distiphallus, oblong in Loxocera s. str. (Figs 9,
10), roughly T-shaped (base abruptly widened) in Imantimyia (e.g., Fig. 30), apical, membranous portion short to long. Phallotrema of Loxocera s. str. very large, flanked by peculiar, short or long, straight or curved, simple or apically bifurcate, cuticular processes (Figs 9, 10: pt pr). Ejaculatory apodeme moderately developed in Loxocera s. str. (Fig. 8: ea), absent or very small in Imantimyia (e.g., Fig. 21)

Discussion of morphology. All species of Loxocera lack surstyli as is typical for the subfamily (Steyskal, 1987; Shatalkin, 2002). The structures Iwasa (1992) interpreted as surstyli in some east Palaearctic Loxocera s. str. are in fact hypandrial lobes. The hypandrial origin of these lobes is clearly demonstrated by the fact that they are continuous with (fused to) the hypandrium, but separated from the epandrium.

Function. The different morphologies described here reflect different functional mechanisms of the male genitalia. The moveability of certain parts of the genitalia can either be observed directly or through comparison of specimens of the same species that died with their genitalia in different functional positions.

Four principal types of movements can be observed in Loxocera genitalia: (1) Hypandrium (plus associated structures) against epandrium. (2) Phallapodemic sclerite (plus phallapodeme) against hypandrium. (3) Postgonite against hypandrium. (4) Phallus against phallapodemic sclerite. The full spectrum of movements occurs only in the $L$. (I.) achaeta- and the L. (I.) fulviventris-species groups. In Loxocera s. str. and apparently L. (I.) albiseta movements (2) and (3) are not enabled. This is due to the fusion or close connection between the phallapodemic sclerite and the hypandrium, which as a consequence also precludes movement (3). Movements (1) and (2) are caused directly by muscle action. In the L. achaeta- and the L. fulviventris-group movements (3) and (4) are indirectly effected through movement of the phallapodemic sclerite against the hypandrium.

\section{Female terminalia}

Morphology. Intersegmental membrane 6-7 very reduced in Loxocera s. str., partially to almost completely sclerotized in Imantimyia. Segment 7 slightly compressed laterally, with a pair of spiracles; pleural area reduced, tergite almost reaching sternite (e.g., Fig. 31). Tergite 7 in some Imantimyia with a pair of paramedian posterior projections, in some species membrane below each projection with a minute pit (Figs 49, 50). Sternite 7 keeled along mid-line (Loxocera s. str.) or flat to slightly convex (Imantimyia). Anterior portion of intersegmental membrane 7-8 permanently exposed, not retractable into segment 7 (Fig. 62: im nr). Ovipositor beyond segment 7 strongly compressed. Segment 8 more or less coriaceous and longitudinally striate, without differentiated tergite and sternite, sometimes with slightly sclerotized areas, especially laterally; without microtrichia except sometimes anteroventrally. Posterodorsal margin of segment 8 shallowly emarginate (Figs 11,12 ) or triangularly incised (e.g., Fig. 65). Segment 8 laterally clearly delimited from following segment (e.g., Fig. 64) or not (Fig. 52); pos- 
teroventral margin simple or with a deep linear incision, sometimes bearing a few long microtrichia. Tergite 10 and cerci separate in Loxocera s. str. (Fig. 11), indistinguishably fused in Imantimyia (e.g., Fig. 12), bearing short setulae and some longer hairs. Sternite 10 with short setulae and few longer hairs, posterior margin with a dense fringe of long microtrichia in Imantimyia (e.g., Fig. 52). Cerci separate and firmly appressed to each other (e.g., Fig. 51) or fused along midline, flattened laterally or dorsoventrally (Figs 51-53). In some species of Imantimyia (L. albiseta and L. fulviventris-group) each cercus bears a pair of peg-like sensilla laterally (probably chemoreceptive basiconic sensilla) (e.g., Fig. 13: ss). This character is noteworthy because it appears to be part of the groundplan of Psilidae and has been preserved in Chyliza (Fig. 14), Psila s. 1. and the more primitive species of Loxocera. Spermathecae not observed, desclerotized as usual in the family.

Discussion of morphology. The small pits that occur behind tergite 7 in most Imantimyia have not been described before in Psilidae. Their function is unknown. A similar structure is present in at least two undescribed species of Psila s. str. from northern Quebec and New Mexico (Buck, unpublished), but in these species the pits are much larger and more conspicuous than in Loxocera.

Discussion of function. The oviposition behaviour of Loxocera has never been observed. Based on its very compressed shape the Loxocera ovipositor was thought to be adapted for piercing tissue of the host plant (Steyskal, 1987; Iwasa, 1998). Examination of the fine structure does not support this hypothesis. The cerci or the fused tergite $10+$ cerci bear several longer hairs dorsally and ventrally, some of which are directed more or less posteriorly (e.g., Figs 53, 65). These hairs would hinder penetration of the plant tissue and would probably break off at the first oviposition attempt. In contrast to the piercing ovipositors of Agromyzidae and Tephritidae, the ovipositor of Loxocera does not possess any raspers or sharp edges enabling it to cut into plant tissue. It seems more likely that the ovipositor is adapted for inserting eggs into narrow crevices. Based on existing knowledge of the host plants of Loxocera (see below) this could be the space between leaf sheaths and stems of Carex or Juncus.

\section{Biology}

All members of the family Psilidae appear to be phytophagous (Steyskal, 1987), though host plants of most species are unknown. The most common eastern Nearctic species of Loxocera, L. cylindrica, breeds in stems of the sedge Carex interior Bailey (Valley et al., 1969), and apparently attacks healthy plants. The European L. albiseta was reared from stems of Juncus effusus L. (de Meijere, 1941). Immature stages are largely unknown except for the two European species L. albiseta (larva: de Meijere, 1945; puparium: de Meijere, 1941) and L. aristata (egg: see Taxonomic treatment of eggs below).

\section{Subgenus Loxocera Meigen, 1803}

Platystyla Macquart, 1835: 374, syn. n. Type species: Loxocera hoffmannseggi Meigen, 1826: 366 (by monotypy).
Included species. Loxocera s. str. in the revised sense is comprised of nine species including four new subgeneric combinations: L. aristata (Panzer, 1801) (Europe, Caucasus); L. atriceps Bigot, 1886 (Europe, Caucasus; species status unclear); L. glandicula Iwasa, 1993 (Nepal); L. hoffmannseggi Meigen, 1826 (Europe); L. maculata Rondani, 1876 (Europe); L. malaisei Frey, 1955, comb. n. (Burma, Nepal); L. matsumurai Iwasa, 1992, comb. n. (Far East); L. monstrata Iwasa, 1992, comb. n. (Japan); and L. omei Shatalkin, 1998, comb. n. (China). The only species examined were $L$. aristata, $L$. hoffmannseggi and L. maculata (material in ZSMC, CNCI). Based on their very brief original descriptions $L$. annulata Wang \& Yang, 1996 and L. tianmuensis Wang \& Yang, 1998 (both from China), which were originally assigned to the subgenus Loxocera, cannot be confidently placed to subgenus.

Monophyly. Loxocera s. str. in the traditional sense (e.g., Hennig, 1941) excluded species with an elongated scape and pedicel (L. hoffmannseggi, L. malaisei), which were placed in a separate subgenus Platystyla. Iwasa (1992, 1998) slightly modified the concept of Platystyla after discovering species with a short scape and pedicel, emphasizing the more distal insertion and thickening of the arista in this subgenus. Frey (1925) was the first author to realize that $L$. (L.) aristata (the type species of Loxocera) and its relatives are not closely related to the remaining species of Loxocera s. str.: He elevated Platystyla and Loxocera s. str. to genus rank and created a new subgenus Imantimyia for the species of Loxocera $\mathrm{s}$. str. outside the L. aristata-group. His classification was not adopted by subsequent authors, and Imantimyia has since been treated as a synonym of Loxocera s. str. (e.g., Hennig, 1941; Soós, 1984). Shatalkin (1998) confirmed L. aristata plus related species as a distinct species group within Loxocera s. str. but continued to use the traditional subgeneric classification. None of the previous workers realized that Platystyla is closely related to the $L$. $(L$.) aristata-group, and that both together form a wellcharacterized monophyletic group. In combining the two groups the name Loxocera retains priority over Platystyla and is hereby instated as the valid name for the clade. The sister group, Frey's Imantimyia, includes the remainder of the species of the previous Loxocera s. str. The characters used by Frey (1925) to define Imantimyia are ambiguous and unsuitable but the monophyly of this subgenus is demonstrated by other characters (see below).

Groundplan. The hypothesized groundplan characters of Loxocera s. str. are listed below (based on examination of the European species L. hoffmannseggi, L. aristata and L. maculata). The corresponding character states found in the sister group Imantimyia are given in parentheses.

Autapomorphic characters (plesiomorphic characters states = groundplan characters of Imantimyia in parentheses): (1) Frontal vitta desclerotized, matt and velvety as in Fig. 3 (sclerotized, at least subshining, not velvety as in Fig. 5). (2) Lunule broadly exposed, extending laterally between base of antenna and anterior margin of frons as in Fig. 3: lu (lunule hidden or only slightly exposed 
between antennal bases as in Fig. 5). (3) Mid coxal prong shortened, more or less appressed to coxo-trochanteral membrane as in Fig. 4: cxp (well developed, distinctly projecting above surface as in Fig. 6: cxp). (4) Alula bare, devoid of microtrichia except along margin (surface microtrichose). (5) Tergite 6 fused to pregenital sclerite (separate). (6) Pregenital sclerite fused to epandrium as in Fig. 7, sclerites delimited from each other by distinct suture (separate). (7) Subepandrial sclerite absent (present as in Figs 45, 46; weakly developed in some species). (8) Hypopygium without cavity between cerci and hypandrial/phallic complex (with large cavity extending anteriorly below cerci, delimited ventrally by hypandrial/phallic complex). (9) Hypandrial plate very reduced or absent as in Fig. 9, not connected to hypandrial arms, which are secondarily fused to phallapodemic sclerite (hypandrial plate moderately developed as in Figs 33,34 , continuous with hypandrial arms, which are separate from phallapodemic sclerite). (10) Hypandrial arms posteroventrally produced into a pair of large shield-like lobes around phallus as in Figs 7-9 (lobes absent). (11) Phallotrema surrounded by cuticular processes as in Figs 9, 10: pt pr (phallotrema simple). (12) Female sternite 7 keeled along midline (not keeled). (13) Female cercus without peg-like sensilla laterally (with two close-set peglike sensilla laterally as in Fig. 13: ss; lost in some Imantimyia).

Plesiomorphic characters (apomorphic characters states = defining characters of Imantimyia in parentheses): (14) Pregenital sclerite large, setulose and exposed: Fig. 7: pgs (small, bare and hidden). (15) Ejaculatory apodeme moderately developed: Fig. 8: ea (very small or absent: e.g., Fig. 33). (16) Female tergite 10 separate from cerci: Fig. 11 (fused: e.g., Fig. 12).

Characters of uncertain polarity (character states of Imantimyia in parentheses): (17) Hypandrial bridge present: Fig. 7: hb. According to drawings provided by Iwasa (1993) the hypandrial bridge might be medially interrupted in L. monstrata and L. matsumurai (hypandrial bridge absent). (18) Phallapodeme with anterior transverse portion: Fig. 8: pa at (transverse portion absent). (19) Phallus oblong: Fig. 10 (T-shaped: e.g., Fig. 30). (20) Postgonite with irregularly serrate posterior margin: Fig. 9 (not serrate). (21) Postgonite in fixed position, pointing ventrally: Fig. 8 (postgonite either moveable or pointing in different direction).

Discussion. The monophyly of Loxocera s. str. is well supported by a large number of unique autapomorphies. Only characters (6) and (9) occur elsewhere in the Psilinae (i.e., in Psila, subgenus Xenopsila), where they have developed independently (Buck \& Marshall, 2006). The monophyly of Imantimyia on the other hand is less strongly supported. The most convincing autapomorphy is the fusion of the cerci with tergite 10 in the female (character 16). The remaining defining characters appear to be prone to homoplasy to at least some degree: The reduction of the pregenital sclerite (character 14) is a widespread condition in Psilidae, and Loxocera s. str. appears to be the only group in the whole family that has preserved a well-developed, setulose pregenital sclerite (tergite 7). Its reduction must therefore have taken place at least three times independently within the family. Two character states of unknown polarity also invite comment: A hypandrial bridge (character 17) is present in Loxocera s. str., Chyliza and apparently in Tropeopsila (Shatalkin, 1998: Fig. 4), and must have been independently lost or gained more than once in the evolution of Psilidae. The transverse phallapodeme (character 18) of Loxocera s. str. is shared with Psilosoma and Psila dimidiata Loew, 1869, where it must have developed independently. The oblong phallus (character 16) of Loxocera s. str. appears to be similar to Tropeopsila (Shatalkin, 1998: Fig. 4), whereas the T-shaped phallus of Imantimyia occurs in very similar form in Psila s. str., indicating further cases of homoplasy.

\section{Subgenus Imantimyia Frey, 1925, stat. restit.}

Imantimyia Frey, 1925: 50. Type species: Nemotelus albiseta Schrank, 1803: 104 (original designation).

Species groups. Loxocera was first divided into species groups by Shatalkin (1998), who recognised four groups, two of which (L. achaeta- and L. fulviventris-group) are now placed in Imantimyia. The taxonomic limits of both groups are corrected and their definitions are based on a more stringent character analysis. The European L. albiseta, which was placed in the L. fulviventris-group by Shatalkin, is removed from this group based on the phylogenetic analysis presented below. It is treated separately here as the only member of the L. albiseta-group. The $L$. fulviventris-group in the revised sense is quite homogeneous and consists of morphologically similar species. This is also true for the L. achaeta-group if the somewhat aberrant Central American species L. ignyodactyla sp. n. is excluded. In the present phylogenetic analysis we include the following four operational taxonomic units: $L$. achaeta-group s. str. (excl. L. ignyodactyla sp. n.), L. ignyodactyla sp. n., L. fulviventris-group, and L. albiseta. Loxocera algerica Villeneuve, 1913, L. chinensis Iwasa, 1996 and L. triplagata Wang \& Yang, 1996 were not available for examination, and their group affiliation remains unknown.

\section{L. achaeta-group}

Included species. L. achaeta Shatalkin, 1989 (Far East, not examined); L. cylindrica Say, 1823 (eastern Nearctic); L. fumipennis Coquillett, 1901 (central Nearctic; wrongly attributed to L. fulviventris group by Shatalkin, 1998); L. ignyodactyla Buck sp. n. (Costa Rica), L. lutulenta Iwasa, 1992 (Far East, $10^{\star}$ examined in CNCI); L. nigrifrons Macquart, 1835 (Europe, material examined in ZSMC); L. ojibwayensis Buck sp. n. (northeastern Nearctic). According to Wang \& Yang (1996) L. lunata Wang \& Yang, 1996 and L. univitatta Wang \& Yang, 1996 from China are closely related to $L$. nigrifrons, and might therefore also belong in the L. achaeta-group.

Monophyly. The monophyly of the L. acheata-group in the strict sense (excl. L. ignyodactyla sp. n.) is established by four apomorphic characters (plesiomorphic character states in parentheses): (A1) Inner space of 
phallic pouch strongly constricted by membranous lateral walls leaving only a narrow median gap: Figs 44, 47 (phallic pouch wide). (A2) Female segment 7 with pair of pits behind tergite 7: Figs 49, 50 (pits absent). (A3) Posterior margin of female tergite 8 indistinctly delimited from following segment laterally: Fig. 52 (distinctly delimited, forming broad rounded lobe: Fig. 64). (A4) Female cercus distinctly dorsoventrally flattened: Figs 51-53 (laterally flattened).

\section{L. fulviventris-group}

Included species. L. collaris Loew, 1869 (= L. californica Capelle, 1953, syn. n., see below) (Nearctic); L. fulviventris Meigen, 1826 (Transpalaearctic, material examined in ZSMC, CNCI); L. microps Melander, 1920 (western Nearctic); L. sylvatica Meigen, 1826 (Europe, material examined in ZSMC, CNCI). According to Wang \& Yang (1996) L. planivena Wang \& Yang, 1996 and L. sinica Wang \& Yang, 1996 from China are similar to $L$. sylvatica, and might therefore also belong in the $L$. fulviventris-group.

Monophyly. The monophyly of the group is established by six apomorphic characters (plesiomorphic character states in parentheses): (F1) Pedicel higher than long as in Figs 17, 18 (at least as long as high as in Figs 19, 20). (F2) First flagellomere somewhat swollen at base as in Figs 17, 18 (not swollen as in Figs 19, 20). (F3) Sternites 2-5 conspicuously desclerotized and folded along mid-line (not desclerotized and folded). (F4) Postgonite with well-defined apical tooth present: e.g., Figs 26-29 (tooth absent, but apex of postgonite more or less tapered: e.g., Figs 39-42). (F5) Postgonite with abundant microtrichia ventrally: e.g., Figs 26-29 (with very few or no microtrichia: e.g., Figs 39-42). (F6) Female cerci completely fused along midline (free: e.g., Fig. 51). According to the phylogenetic analysis (see below) the enlarged, plate-like hypandrial arms (see character 5 below) comprise another synapomorphy for the species group. This character appears to have evolved independently in L. albiseta.

\section{L. albiseta-group}

Included species. L. albiseta (Schrank, 1803) (Europe, material examined in ZSMC, CNCI). According to Wang \& Yang (1996) L. pauciseta Wang \& Yang, 1996 from China is closely related to L. albiseta, and might therefore belong in the same group.

Autapomorphic characters (plesiomorphic character states in parentheses). - (L1) Phallapodemic sclerite with very long posterior arms (arms shorter). (L2) Phallapodeme asymmetrically continued as ridge on internal surface of left arm of phallapodemic sclerite (continued symmetrically on both arms of phallapodemic sclerite). (L3) Postgonite completely rounded distally: Fig. 15 (either toothed or tapered: e.g., Figs 36-42).

\section{Species-group relationships within Imantimyia:}

Phylogenetic analysis. The analysis is based on a 10character matrix (Table 1), including the following char-
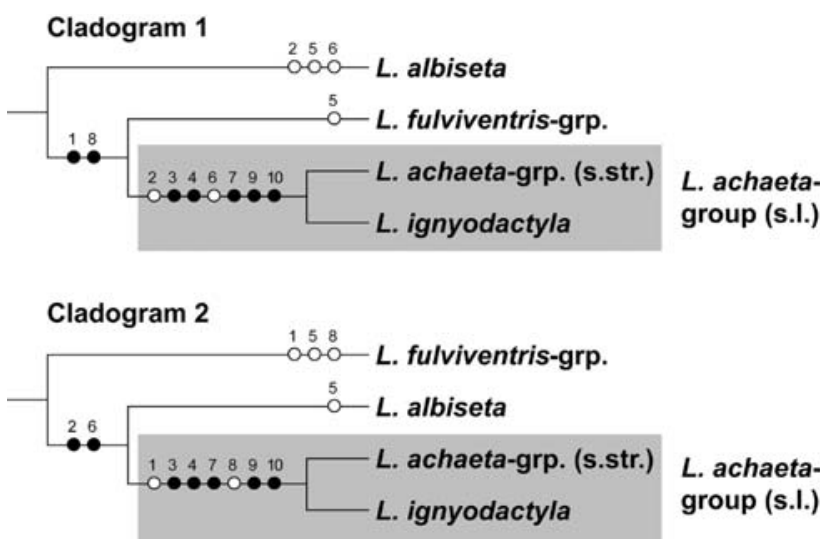

Fig. 16. Phylogeny of species groups of Loxocera (Imantimyia). Explanations: Circles represent apomorphic character states (black circles $=$ unique synapomorphies, open circles $=$ convergences; character number given above circles, characters explained in text). Tree statistics: tree length $=13$, consistency index $(\mathrm{CI})=0.769$, retention index $(\mathrm{RI})=0.700$. Character matrix see Table 1.

acters (plesiomorphic character state coded 0; apomorphic character state coded 1):

(1) Gena, short silvery pubescence: present -0 ; absent - 1. (2) Arista pubescence: short - 0 (e.g., Figs 17, 18); long - 1 (e.g., Figs 19, 20). (3) Wing pattern/infuscation: absent - 0; present - 1. (4) Phallic pouch, inner membranous surface: smooth -0 ; sculptured with spinules or rounded scales (Fig. 47) - 1. (5) Hypandrial arms: relatively slender - 0; forming large, vertical plates (e.g., Fig. 33: hy) - 1. (6) Ejaculatory apodeme: present - 0; absent - 1. (7) Postgonite insertion on phallapodemic arms: apical or preapical (e.g., Fig. 34) - 0; near middle (e.g., Fig. 58) - 1. (8) Postgonite moveability: fixed - 0; moveable - 1. (9) Female tergite 10, shape: not or very little projecting anteriorly (Fig. 12) - 0; strongly projecting anteriorly into segment 8 (e.g., Fig. 65) - 1. (10) Female cercus: with two peg-like sensilla (Fig. 12) - 0; without sensilla -1 .

Discussion. The data support two equally most parsimonious cladograms (Fig. 16) that differ with regard to the position of L. albiseta. Cladogram 1 with L. albiseta as the sister group of the remaining Imantimyia species seems slightly more likely than cladogram 2 with this species as the sister species of the L. achaeta-group. Shatalkin (1998) included L. albiseta in the $L$. fulviventris-group because of the apical position of the postgonites (character 7), which he considered apomorphic. However, this is not supported by comparison with staggered outgroups (Loxocera s. str. - Tropeopsila -

TABLE 1. Character matrix for phylogenetic analysis of species groups in Imantimyia.

\begin{tabular}{lcccccccccc}
\hline Character \#: & 1 & 2 & 3 & 4 & 5 & 6 & 7 & 8 & 9 & 10 \\
\hline L. albiseta & 0 & 1 & 0 & 0 & 1 & 1 & 0 & 0 & 0 & 0 \\
L. fulviventris-group & 1 & 0 & 0 & 0 & 1 & 0 & 0 & 1 & 0 & 0 \\
L. achaeta-group (s. str.) & 1 & 1 & 1 & 1 & 0 & 1 & 1 & 1 & 1 & 1 \\
L. ignyodactyla sp. n. & 1 & 1 & 1 & 1 & 0 & 1 & 1 & 1 & 1 & 1 \\
\hline
\end{tabular}



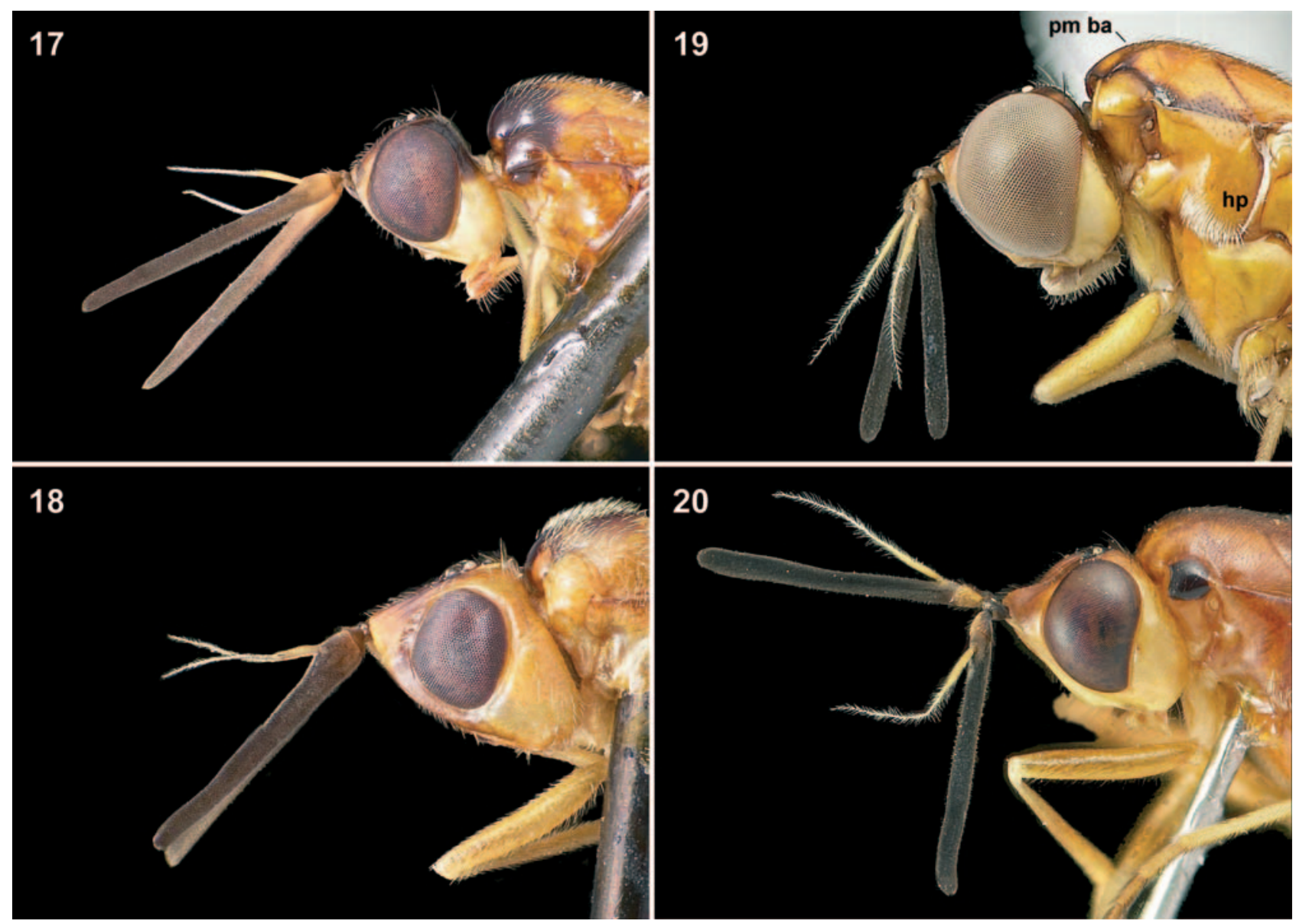

Figs 17-20. Head and anterior portion of thorax of Loxocera (Imantimyia), lateral view: 17 - L. collaris, male (Canada, New Brunswick); 18 - L. microps, male (paratype; USA, Washington); 19 - L. ojibwayensis sp. n., female (paratype; Canada, Ontario); 20 - L. ignyodactyla sp. n., male (holotype; Costa Rica, Puntarenas). pm ba - posterior margin of bare area of mesonotum, hp patch of downcurved hair on anepisternum.

Psila s. 1.; ordered by decreasing degree of relatedness), all of which have apically or preapically inserted postgonites. Basally inserted postgonites do occur in derived subgroups of Psila s. 1., but these are clearly cases of convergence (Buck \& Marshall, 2006).

The sister group relationship between the Neotropical L. ignyodactyla sp. $\mathrm{n}$. and the Holarctic remainder of the L. achaeta species group is strongly supported by characters $3,4,7,9$ and 10, especially by the basal insertion of the postgonites (character 7). It is noteworthy that the loss of peg-like sensilla (character 10) has occurred independently in Loxocera s. str. (see above).

\section{Taxonomic treatment: adults}

\section{Key to adults of the New World species of Loxocera}

Note: All New World species of Loxocera belong to the subgenus Imantimyia.

1 Wing with a transverse brown band at level of posterior cross vein, apex hyaline (Fig. 55). Face (between parafacials) and frontal orbits without microtomentum. Male hind femur with slender posteroventral process (Fig. 56). Postgonite moderately sclerotized, pale brown (Fig. 60). Large species, ca. $12 \mathrm{~mm}$ (Costa Rica). . . . . . . . . . . . . . .
- Wing unpatterned or infuscated at apex and around posterior cross vein, lacking transverse band (Fig. 54). Face laterally (including parafacials) and lower frontal orbits with silvery to brown microtomentum. Male hind femur simple. Postgonite strongly sclerotized, dark brown with black apex. Smaller species, 6-8 $\mathrm{mm}$ (Nearctic). . . . . . . . . . . 2

2 Pedicel short, higher than long (Figs 17, 18). Wing hyaline. Tergite 1 smooth, with minute transverse wrinkles or minute roughening. Sternites 2-5 longer than broad, desclerotized and conspicuously folded along midline. Postgonite short and rounded, with slender apical process (Figs 26-29, 36, 37). Female cerci laterally compressed and completely fused along midline. . . . . . . . . . . fulviventris-group 3 - Pedicel long, longer than high (Figs 19, 20). Wing patterned or evenly infuscated. Tergite 1 distinctly rugose. Sternites $2-5$ at least as broad as long (except sometimes S2), neither desclerotized (or just slightly so) nor folded medially. Postgonite elongate, tapered at one or both ends (Figs 39-42, 48). Female cerci dorsoventrally flattened, separate but firmly appressed to each other (Figs $51-53$ ). . . . . . . . ....................... L. achaeta-group, in part 4 

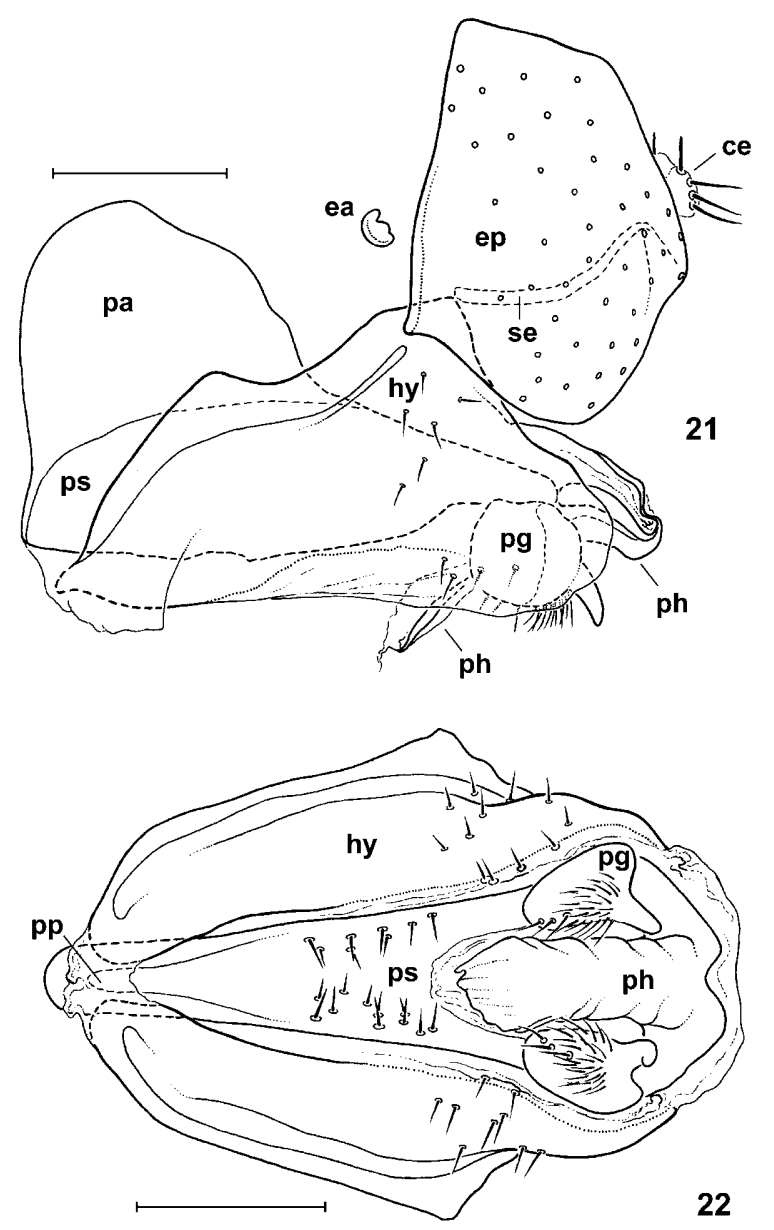

Figs 21-22. Male genitalia of Loxocera (Imantimyia) collaris (Canada, Nova Scotia): 21 - lateral view; 22 - ventral view. Scale $0.1 \mathrm{~mm}$. ce - cercus, ea - ejaculatory apodeme, ep - epandrium, hy - hypandrium, pa - phallapodeme, pg - postgonite, ph - phallus, pp - phallic pouch, ps - phallapodemic sclerite.

3 Vertical bristles short, inner vertical shorter than distance between its socket and midline. Parafacial broad (Fig. 18), at least $2.0 \times$ as wide as swollen basal part of arista. First flagellomere relatively short (Fig. 18), 1.8-1.9× (đ) or $1.3-1.5 \times($ ㅇ $)$ as long as face. Hind tibia with anteroventral apical bristle hardly differentiated from surrounding hairs. Postgonite as in Figs 36, 37 (western Nearctic). . L. microps

- Vertical bristles long, inner vertical at least as long as distance between its socket and midline. Parafacial narrower (Fig. 17), at most $1.5 \times$ as wide as swollen basal part of arista. First flagellomere long (Fig. 17), 2.3-3.0× (đ) or 1.9-2.6× () as long as face. Hind tibia with distinct anteroventral apical bristle. Postgonite as in Figs 26-29 (Nearctic)........................ L. collaris

4 Scutum: length of bare area behind anterior declivity approximately as long as postpronotal lobe (Fig. 19). Male postgonite sickle-shaped, tapered at both ends (Fig. 48). Wing patterned (Fig. 54). Arista long-pubescent (Fig. 19) (Ontario)..................... ojibwayensis sp. n.

- Scutum: length of bare area behind anterior declivity at most half as long as postpronotal lobe. Male postgonite with rounded base, tapering towards apex (Figs 39-42). Wing and arista variable.....................
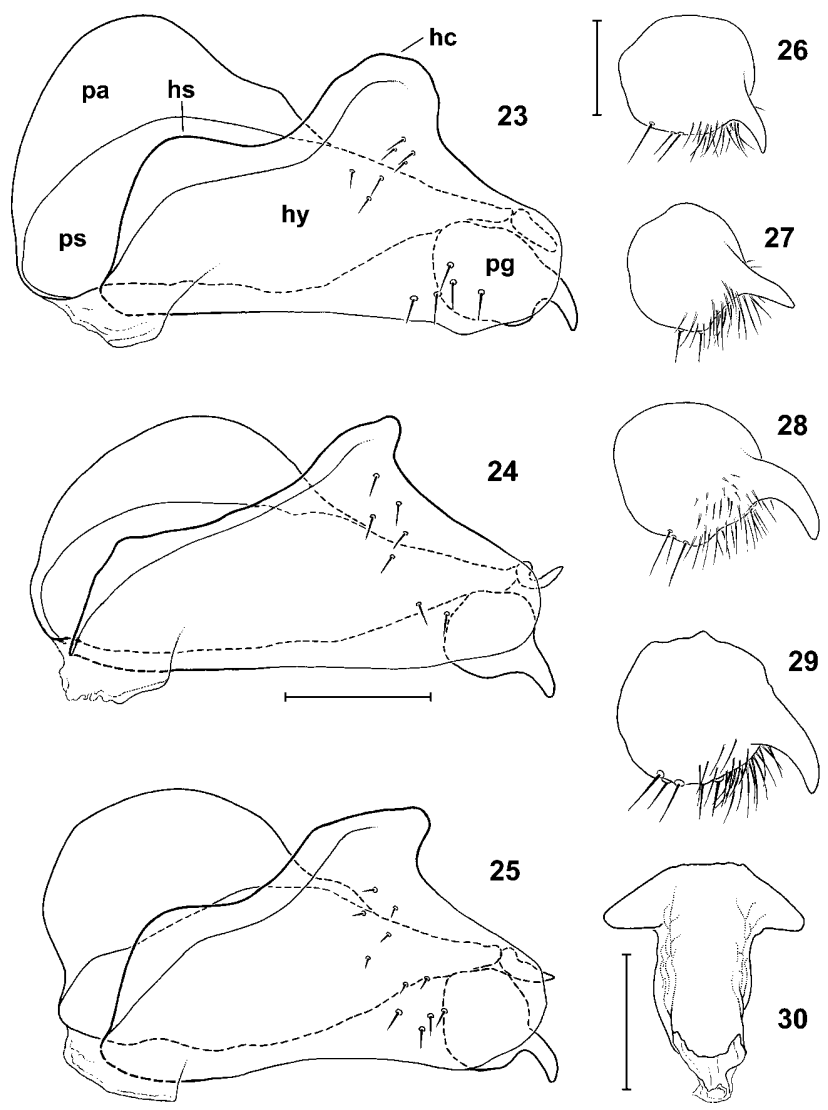

Figs 23-30. Male genitalia of Loxocera (Imantimyia) collaris (showing individual variation). Hypandrium, lateral view: $23-$ USA, Oregon; 24 - USA, California; 25 - Canada, New Brunswick. Right postgonite, inner lateral view: 26 - holotype of $L$. californica syn. n.; 27, 28 - USA, Tennessee; 29 - Mexico, Durango. Phallus, posterior view: 30 - Mexico, Durango. Scale $0.05 \mathrm{~mm}$ (postgonites) and $0.1 \mathrm{~mm}$ (others). hy - hypandrium, hc - hypandrium, dorsal condyle, hs - hypandrium, anterodorsal shoulder, pa - phallapodeme, pg - postgonite, ps - phallapodemic sclerite.

5 Wing evenly infuscated. Arista short-pubescent (as in Fig. 17), longest rays as long as diameter of swollen base of arista. Postgonite more elongate (Fig. 41, 42), with more slender and more curved apex than in L. cylindrica (central Nearctic). ................. Lumipennis - Wing infuscated at apex, around posterior crossvein and penultimate sector of $\mathrm{M}$ (as in Fig. 54). Arista longpubescent (as in Fig. 19), longest rays twice as long as diameter of swollen base of arista. Postgonite shorter (Figs 39, 40), with stouter and less curved apex than in $L$. fumipennis (eastern Nearctic).............. L. cylindrica

\section{Loxocera fulviventris -group}

Diagnosis. Bare, non-tomentose, median strip of face almost reaching base of antennae (except in L. microps). Eye generally smaller (eye height $1.6-3.2 \times$ genal height) than in L. achaeta-group. Pedicel higher than long, first flagellomere with somewhat swollen base, especially in male (Figs 17, 18). Arista (Figs 17, 18) distinctly removed from base of first flagellomere (inserted clearly distal of apicoventral margin of pedicel). Arista shortpubescent, longest rays as long as diameter of swollen 

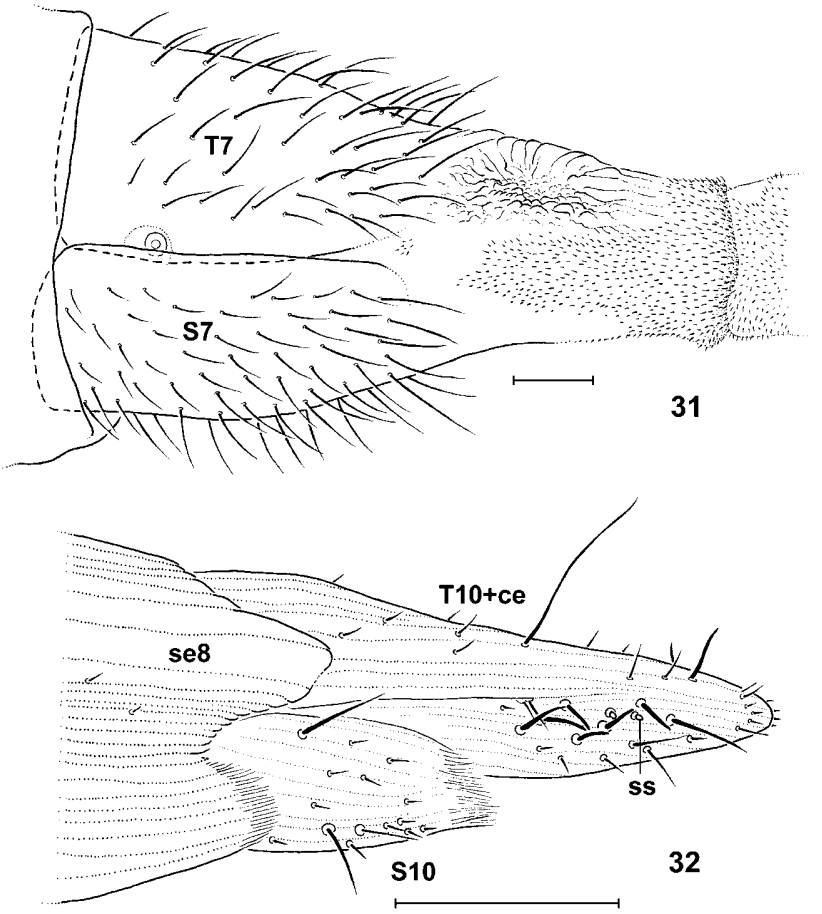

Figs 31-32. Ovipositor of Loxocera (Imantimyia) collaris (USA, Tennessee): 31 - segment 7, lateral view; 32 - apex of ovipositor, lateral view. Scale $0.1 \mathrm{~mm}$. ce - cercus, se 8 - segment 8 , ss - peg-like sensilla, $\mathrm{S}$ - sternite, $\mathrm{T}$ - tergite.

base of arista. Wing not infuscated. Tergite 1 smooth, with very fine wrinkles or roughening. Sternites 2-5 longer than broad, desclerotized and conspicuously folded along midline. Male terminalia: Dorsal portion of subepandrial sclerite well developed, ventral portion poorly developed to absent. Hypandrium large, forming large, conspicuous, almost vertical plates (Figs 21, 33: hy), largely ventral to epandrium even in resting position. Phallic pouch poorly developed, not spinulose. Phallapodeme connected to phallapodemic sclerite throughout its entire length (e.g., Fig. 21: pa). Phallapodemic sclerite with scattered setulae, lacking setulose protuberances at base of posterior arms. Postgonites inserted at apex of phallapodemic arms (Fig. 34); shape rounded with apical process; ventral portion with abundant, long microtrichia and a few hairs (Figs 26-29, 36, 37). Ejaculatory apodeme small to minute but well sclerotized (e.g., Fig. 21). Female terminalia: Intersegmental area between segments 6 and 7 long, ca. 1/3 as long as segment 6 ; intersegmental membrane sclerotized laterally and ventrally. Female tergite 7 anteromedially produced (projection hidden below previous tergite, only visible in cleared specimens). Segment 7 without tiny pits behind tergite 7 . Segment 8 with more or less developed, sclerotized, lateral strips; posterior margin slightly incised dorsally, laterally clearly delimited from following segment and forming distinct rounded lobe. Cerci laterally compressed and completely fused along midline. Two peg-like sensilla present on each cercus (Fig. 32: ss).

\section{Loxocera collaris Loew, 1869}

(Figs 17, 21-32)

Loxocera collaris Loew, 1869: 184.

Loxocera californica Capelle, 1953: 106, syn. n.

Diagnosis. Bare, non-tomentose, median strip of face extending to level of antennae, narrow near dorsal end and restricted to median carina. Parafacial narrow (Fig. 17), width less than ocellar diameter; eye large, in lateral view almost attaining anterior margin of head. Eye height

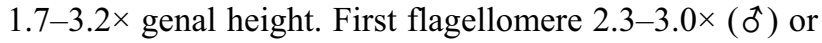
$1.9-2.6 \times($ O ) as long as face (Fig. 17). Pleuron with or without black markings. Hind tibia with well developed anteroventral apical bristle. Median desclerotized area of male sternite 6 triangular, widening posteriorly. Male genitalia: Hypandrium height ca. $0.5 \times$ its length, shape of anterodorsal shoulder and dorsal condyle (for articulation with epandrium) somewhat variable (Figs 21, 23-25: hc, hs). Phallapodeme large, size very variable (Figs 21, 23-25: pa). Phallapodemic sclerite parallel-sided, not expanded anteriorly (Fig. 22: ps). Postgonite variable, especially with regard to development of apical spine (Figs 26-29), more rounded than in L. microps. Phallus without pair of short processes at base (Fig. 30). Female ovipositor as in Figs 31, 32.

Discussion of synonymy. Like other species in the genus, L. collaris is quite variable, especially in coloration, genal width, length of antenna, shape of postgonite and development of the phallapodeme. Capelle (1953), who examined only one male of $L$. collaris when describing his new species L. californica, was obviously unaware of this variability. After studying long series of L. collaris from various localities and additional material of "californica" from Mexico it became clear that the latter is just a variety of the former. The length of the ocellar bristles especially the vertical bristles, which were Capelle's main diagnostic characters, and also the eye height is less on average in western specimens but eastern specimens sometimes also have shorter bristles. The darker coloration of the thorax and abdomen of "californica" might be climatically induced because all available specimens are from higher elevations. Specimens from comparable elevations in the east (Tennessee: Great Smoky Mts) show the same dark body pattern as described for "californica". No difference between eastern and western specimens was found in other diagnostic characters used by Capelle (1953) like the length of first flagellomere, body size, length of body hair, head shape and shape of postgonite. The latter varies considerably in size and curvature of the posterior spine even among specimens from the same locality (e.g., Figs 27, 28). The unusual shape of the basal portion of the postgonite in "californica" as depicted in Capelle's Fig. 7 was not confirmed by examination of the holotype (Fig. 26). No differences were found between the eggs of eastern and Mexican specimens (eggs from specimens from the western US were not available).

Type material. L. collaris: not examined (MCZC).

L. californica: Holotype $\delta$, USA, California, Sequoia Natl. Pk., 6.viii.1940, R.H. Beamer (SEMC). Paratypes: $3 \hat{o}, 1$, 
USA, California: 20, 19 , Mono Lake, 31.vii.1940, R.H. Beamer (SEMC); 10ิ, Yosemite Natl. Pk., 1.viii.1940, D.E. Hardy (SEMC). (One paratype $q$ from Huntington Lake, California at CASC not examined).

Other material examined. Canada. Newfoundland: $1 \hat{0}$, Portugal Cove, 10.viii.1967, J.F. McAlpine (CNCI); 4ð, St. John's, Agric. Exp. Stn., 5., 6. and 9.viii.1967, malaise trap, J.F. McAlpine (CNCI). Nova Scotia: 60, Bridgetown, 29.viii. and 2.ix.1912, "G[?] E S" (CNCI, 1 DEBU); 1 ते Kentville, 6.viii.1958, J.R. Vockeroth (CNCI); 1 ô Aldershot, 15.viii.1950, A. McPhee (CNCI); 1 \% , Truro, 9.viii.1919, "W" (CNCI). New Brunswick: St. Andrews, 10 1.viii.1978, S.A. Marshall, 10 , 19.viii.1978, Marshall \& Konecny (DEBU); 10 , Kouchibouguac Natl. Pk., 7.ix.1977, S.J. Miller (CNCI). Ontario: 10 , Prescott, 5.ix.1977, K.N. Barber (DEBU); 1 $\widehat{0}$, Icewater Creek watershed, ca. $12.7 \mathrm{~km}$ NNE Searchmont, mi. 10.5 Whitman Dam Rd., 21.-28.vii.1986, riparian meadow - alder thicket, malaise trap, K.N. Barber (DEBU). USA, Virginia: 10 , Blacksburg, 2100 ft, 29.v.1962, J.R. Vockeroth (CNCI); 1 \% , Giles Co., Bald Knob $10 \mathrm{~km} \mathrm{NW}$ Blacksburg, 28.v.2005, S.M. Paiero (DEBU). Tennessee: $8{ }^{\star}, 7 \uparrow$, Great Smoky Mts Natl. Pk., Collins Gap, 5700 ft, 22.viii.1957, J.G. Chillcott (CNCI); 60ิ, 3 ㅇ, same data as previous except: Clingmans Dome, $6600 \mathrm{ft}$ (CNCI); 10,29 , same as previous except: Indian Gap to Clingmans Dome, 5200-6600 ft, 6.viii.1957 (CNCI). North Carolina: 10, Mt. Mitchell, 12.viii.1957, L.A. Kelton (CNCI); 10 , Mitchell Co., Roan Mt., 6200 ft, 13.viii.1957, J.G. Chillcott (CNCI). Oregon: 10, Lincoln Co., Saddleback Mt., 12.ix.1959, J.C. Dirks-Edmunds (USNM); 10, Benton Co., $5 \mathrm{mi}$ WNW Corvallis, 15.ix.-1.x.1984, D.C. Darling (ROME). California: 10, Sequoia Natl. Park, Stony Creek, 5.vii.1947, W.W. Wirth (USNM). Mexico, Durango: 11 $\widehat{\jmath}, 5 \uparrow, 10 \mathrm{mi} \mathrm{W}$ El Salto, 9000 ft, 10.vi.-3.vii.1964 (various dates), J.F. McAlpine (CNCI); 1 o, $24 \mathrm{mi} \mathrm{W}$ La Ciudad, 7000 ft, 28.vi.1964, W.R.M. Mason (CNCI).

Distribution. Widespread in the northeastern Nearctic, in the Appalachians south to North Carolina and Tennessee; in the west from Montana, Idaho and Washington (Capelle, 1953) south to California; also in Durango, Mexico at high elevations. The species has not been recorded from either the midwestern US or the western half of Canada. The apparent gap between eastern and western populations probably does not reflect the actual distribution of this rarely collected species.

\section{Loxocera microps Melander, 1920}

(Figs 18, 33-38)

Loxocera microps Melander, 1920: 92.

Diagnosis. Upper $1 / 5-2 / 5$ of face with sparse microtomentum; bare, non-tomentose, median strip of face restricted to lower 3/5-4/5. Parafacial broad (Fig. 18), width at narrowest point ca. $2 \times$ ocellar diameter; eye small, in lateral view broadly separated from anterior margin of head. Eye height $1.3-2.1 \times$ genal height. First flagellomere $1.8-1.9 \times$ (ठ (Fig. 18). Katepisternum more or less darkened ventrally. Hind tibia with anteroventral apical bristle hardly differentiated from surrounding hairs. Median desclerotized area of male sternite 6 parallel-sided, not widening posteriorly. Male genitalia: Cercus (Fig. 33: ce) better developed than in L. collaris, with more numerous hairs, apex distinctly pointing ventrally. Hypandrium (Fig. 33: hy) very large, height ca. $0.8 \times$ its length. Phallapodeme relatively small (Fig. 33: pa). Phallapodemic sclerite
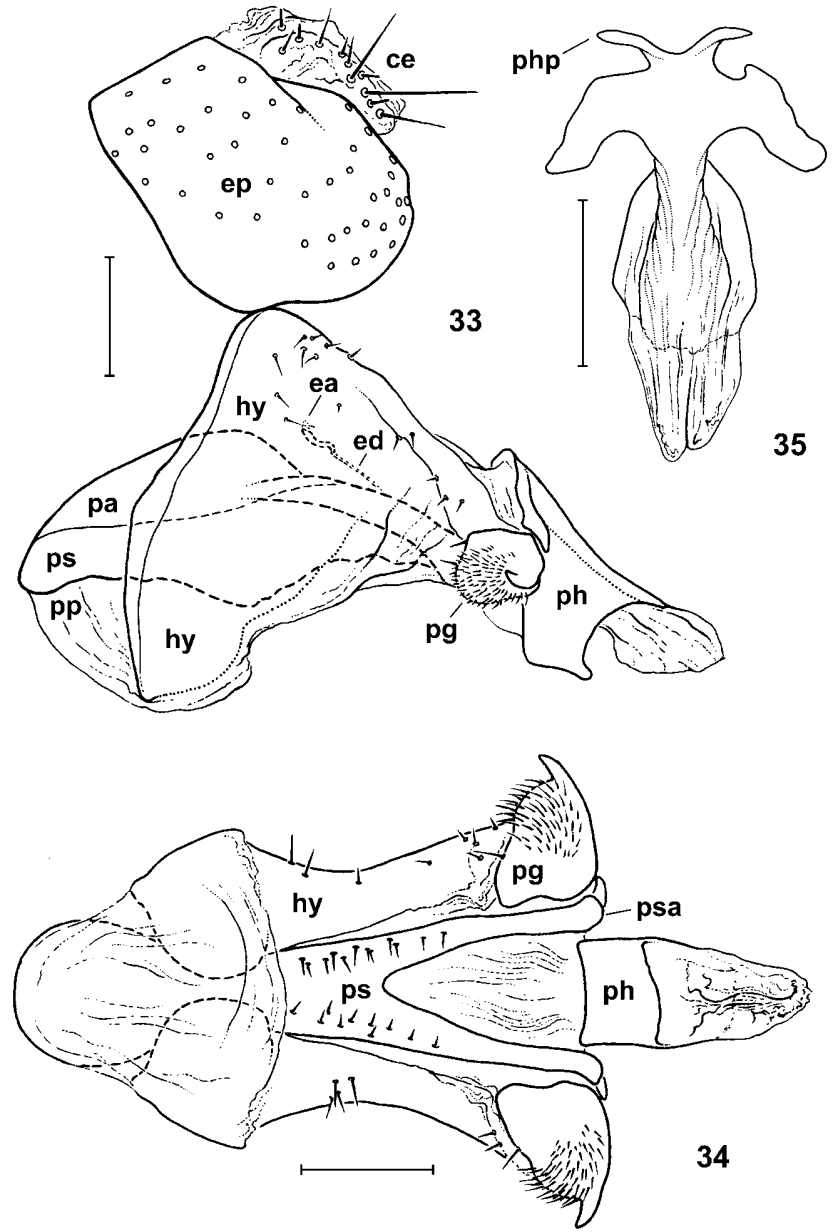

Figs 33-35. Male genitalia of Loxocera (Imantimyia) microps (paratype; USA, Washington): 33 - lateral view; 34 - ventral view; 35 - phallus, caudal view. Scale $0.1 \mathrm{~mm}$. ce - cercus, ea ejaculatory apodeme, ed - ejaculatory duct, ep - epandrium, hy - hypandrium, pa - phallapodeme, pg - postgonite, ph phallus, php - phallus, basal process, $\mathrm{pp}$ - phallic pouch, ps phallapodemic sclerite, psa - ditto, apex of posterior arm(s).

expanded anteriorly (Fig. 34). Postgonite (Figs 36, 37) more triangular than in other Nearctic species of $L$. fulviventris-group. Phallus with a pair of short processes at base (Fig. 35: php). Female ovipositor very similar to L. collaris.

Variation. The coloration of this species is extremely variable. Southern specimens (incl. the paratype, Fig. 18) and a male from Willow, Alaska are predominantly ochreous with largely brown abdomen, restricted dark brown markings on the mesoscutum, dark brown ocellar tubercle, and usually some infuscation of the frons, lower portion of katepisternum and postnotum. On the contrary, specimens from the Yukon Territory, and Unalakleet, Alaska, are almost completely blackish brown excluding anterior margin of frons narrowly, lateral portions of face, lower eye margin, anterior vertical stripe of gena, anterior face of all coxae, knees, tibiae distally, and tarsi. An unusual character for Psilidae is the presence of a few setulae on the meron of some specimens. The unusual shape of the postgonite illustrated by Capelle (1953: Plate 


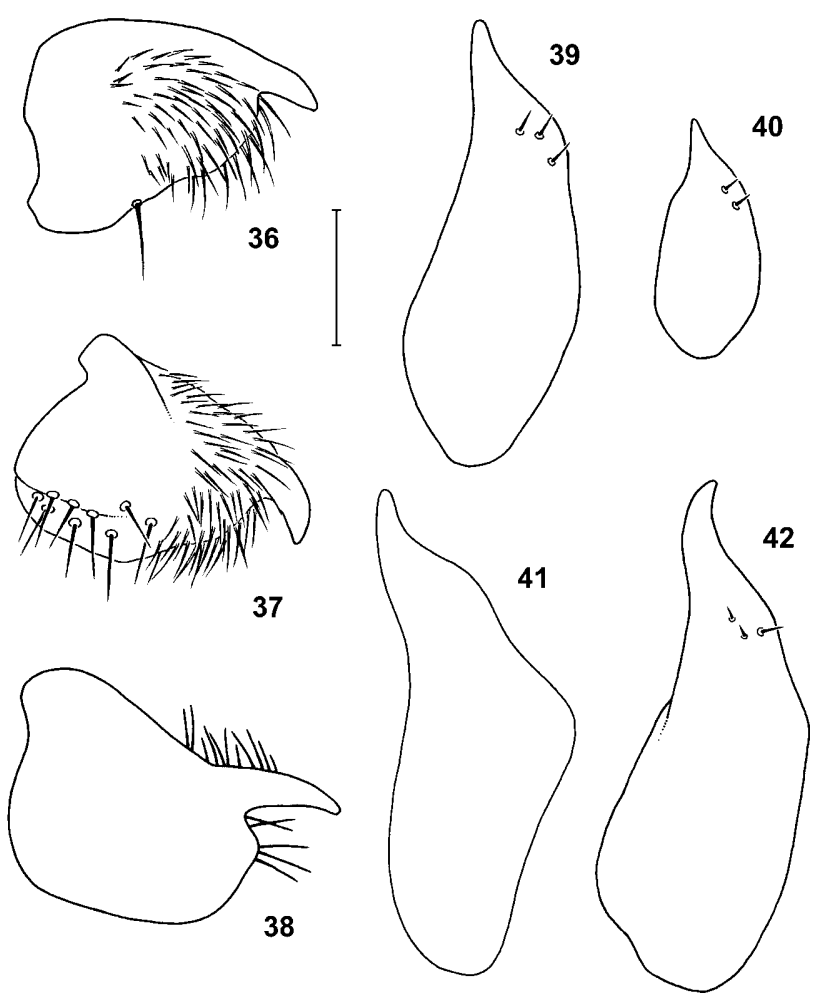

Figs 36-42. Postgonites of Loxocera (Imantimyia). $L$. microps: 36, 37 - paratype, USA, Washington; 38 - redrawn from Capelle (1953: Plate II, Fig. 8). L. cylindrica: 39, $40-$ Canada, Ontario (showing allometric variation). L. fumipennis: 41 - redrawn from Capelle (1953: Plate II, Fig. 5); 42 - USA, Colorado. Lateral inner view except following: 37 - anterior view; 38, 41 - angle of view unknown. Scale $0.05 \mathrm{~mm}$ (unknown for 38, 41).

2, Fig. 8) (reproduced in Fig. 38) is probably due to distortion of the specimen and/or inaccurate illustration. The postgonite of the paratype (with identical collection data as holotype) is depicted in Figs 36, 37.

Type material. Holotype $\widehat{\delta}$, USA, Washington, Mt. Rainier, Paradise Park, viii.1917, A.L. Melander (USNM, not examined). Paratype: $1 \delta^{\hat{t}}$, same data as holotype (USNM).

Other material examined. Canada. British Columbia: $2 \hat{\sigma}$, 1옹 Lisadele Lk., $58^{\circ} 41^{\prime} \mathrm{N} 133^{\circ} 4^{\prime} \mathrm{W}, 4000 \mathrm{ft}$, 7.viii.1960, R. Pilfrey \& W.W. Moss (CNCI); $1{ }^{\star}$, Moosehorn Lk., $58^{\circ} 10^{\prime} \mathrm{N}$ $132^{\circ} 7^{\prime} \mathrm{W}, 4500$ ft, 27.vii.1960, W.W. Moss (CNCI); 1 ㅇ, Mt. Revelstoke, 6200 ft, 18.viii.1952, G.J. Spencer (CNCI); 1 \% , Mt. Revelstoke Natl. Pk., Eva Lk. Trail, 6000 ft, 14.viii.1952, G.J. Spencer (CNCI). Yukon Territory: $10^{\dagger}$, Firth River, 17.vii.1956, R.E. Leech (CNCI); $10^{\star}$, Dempster Hwy km 420, 66 $35^{\prime} \mathrm{N}$, $136^{\circ} 18^{\prime} \mathrm{W}, 3 .-7 . v i i .1979$, malaise trap, ROM field party (ROME). USA. Alaska: 1 \%, Unalakleet, 5.vii.1961, R. Madge (CNCI); 1 đิ, Willow, 18.vii.1948, F.S. Blanton (USNM). Washington: 10, Mt. Rainier, Yakima Park, 22.vii.1924, A.L. Melander (USNM); 1 , (labelled "Parallotype" by Capelle), Mt. Rainier Natl. Pk., 16.viii.1941, L.J. Lipovski (SEMC). Idaho, 1\%, Priest Lake, Lookout Mt., 20.viii.1919, A.L. Melander (USNM).

Distribution. Northwestern Nearctic from Alaska and the Yukon Territory south to Washington and Idaho.

\section{Loxocera achaeta-group}

Diagnosis. Upper $2 / 5$ of face completely tomentose (bare in L. ignyodactyla sp. n.). Eye large (eye height 2.7-7.6× genal height). Pedicel longer than high (Figs 19, 20), base of first flagellomere not swollen. Arista (Figs 19,20 ) inserted close to base of first flagellomere (at or slightly beyond level of apicoventral margin of pedicel). Arista long-pubescent, longest rays twice as long as swollen base of arista (short in L. fumipennis). Wing weakly patterned or evenly infuscated. Tergite 1 strongly rugose (except in L. ignyodactyla sp. n.). Sternites $2-5$ or $3-5$ at least as broad as long, not conspicuously desclerotized and folded medially. Male genitalia: Dorsal portion of subepandrial sclerite partially to completely desclerotized (Fig. 46: se dp), ventral portion well developed (Fig. 45: se vp). Hypandrium moderately developed, hypandrial arms not large and plate-like (e.g., Fig. 43: ha). Phallic pouch membranous, with spinulose inner surface (Fig. 47). Phallapodeme usually free anteriorly (Fig. 43: pa), and separate from phallic pouch (fused in L. ignyodactyla sp. n.). Phallapodemic sclerite usually with a pair of setulose protuberances at base of posterior arms (Fig. 44: pst) (absent in L. ignyodactyla sp. n.), otherwise with few to many setulae. Postgonites articulated near middle of phallapodemic arms (e.g., Fig. 44: pg); shape slender, tapered on one or both ends (e.g., Figs 39-42, 48), bearing a few setulae, rarely also with a few microtrichia (Fig. 60). Ejaculatory apodeme apparently absent. Female terminalia: Intersegmental area between segments 6 and 7 apparently absent, i.e. intersegmental membrane completely sclerotized except for pleural membrane, distinguished from tergites or sternites by absence of bristles. Tergite 7 with straight anterior margin. Segment 7 with a tiny pit behind tergite 7 (Figs 49, 50) (absent in L. ignyodactyla sp. n.). Segment 8 without sclerotized lateral strips, posterior margin deeply incised dorsally (e.g., Fig. 51 ), usually poorly delimited from following segment laterally (Fig. 52: se8) (well delimited in L. ignyodactyla sp. n.). Cerci usually dorsoventrally depressed (laterally compressed in L. ignyodactyla sp. n.), not fused along midline (Figs 51-53).

\section{Loxocera cylindrica Say, 1823}

(Figs 1, 39-40)

Loxocera cylindrica Say, 1823: 98.

Loxocera pleuritica Loew, 1869: 38.

Loxocera pectoralis Loew, 1869: 38.

Loxocera cylindrica var. obsoleta Johnson, 1920: 15.

Diagnosis. Habitus as in Fig. 1. Extent of black markings of thorax very variable (described by Johnson, 1920; geographical variation studied by Capelle, 1953); infuscation of wing also variable. Gena on average slightly higher than in L. ojibwayensis sp. n., eye height 3.8-5.8× genal height. Scutum: length of bare area behind anterior declivity at most half as long as postpronotal lobe. Male genitalia very similar to L. ojibwayensis sp. n., except postgonite. Postgonite (Figs 39-40) with pointed apex and rounded base, apex stouter than in L. fumipennis. Shape of postgonite subject to allometric variation similar 
to L. ojibwayensis sp. n.: postgonite stouter, and margin next to setulose patch more convex in large (Fig. 39) than in small males (Fig. 40). Female ovipositor similar to $L$. ojibwayensis sp. n. (see below).

Taxonomy. The type of L. cylindrica is destroyed and Say's (1823) description is inadequate to distinguish this species from the very similar L. ojibwayensis $\mathrm{sp}$. $\mathrm{n}$. (described below). Considering that the new species is rare and only known from the type locality but L. cylindrica (in the interpretation of previous authors) is common and widespread, we continue to apply this name to the common species, i.e. we are using it as a senior synonym of L. pleuritica, L. pectoralis and L. obsoleta. Lectotypes of the latter two are designated to clarify the identity of these nominal species with regard to $L$. ojibwayensis $\mathrm{sp} . \mathrm{n}$.

Type material. L. cylindrica. "Inhabits Pennsylvania"; destroyed (Capelle, 1953).

L. pectoralis. Holotype, USA, Washington [D.C.] (see Loew, 1869, not mentioned on labels), "Loew Coll.", "pectoralis m", "Type 13334" (MCZC).

L. pleuritica. Lectotype $\widehat{\delta}$ (M. Buck, by present designation): USA, New York, Schoharie Co., "Sharon Springs", "Loew Coll.”, "pleuritica m.", “Type 13335” (MCZC). Paralectotypes not examined (Capelle, 1953, erroneously considered a specimen from Connecticut to be the only type specimen of this taxon).

L. cylindrica var. obsoleta. Lectotype $\widehat{\delta}$ (M. Buck, by present designation): USA, "Plymouth Mass VII 2883 [?]", "Cotype No", "CW Johnson Collector", "M.C.Z. Paratype 27036" (first letters struck through) (MCZC). Paralectotypes not examined.

Other material examined. $179 \widehat{\jmath}, 237 \%$, (CNCI, DEBU, ROME, SEMC, USNM; only marginal localities given). Canada. Every province from Newfoundland to Manitoba (Ninette, CNCI). USA. New Hampshire, Vermont, Massachusetts, Connecticut, New York, Pennsylvania, Ohio, Michigan, Wisconsin, Iowa, Maryland, Virginia, Kentucky, Tennessee, North Carolina, South Carolina (Aiken Co.: Aiken, CNCI; Charleston Co.: Francis Marion Natl. Forest, Santee River, DEBU; Charleston Co.: Hobcaw Barony, Belle Baruch Marine Field Stn., DEBU), Georgia (Floyd Co.: Cave Spring, CNCI), Missouri, Kansas (Kiowa Co.: 7.6 mi SE Haviland, SEMC), Mississippi, Louisiana, Texas (Austin, DEBU; Navasota, CNCI; Liberty Co.: 16 mi E Cleveland, DEBU).

Distribution. Widespread in the eastern Nearctic excluding the extreme southeast, west to Manitoba, Minnesota, Nebraska, central Kansas, Arkansas and eastern Texas (in part after Capelle, 1953).

\section{Loxocera fumipennis Coquillett, 1901}

(Figs 41-42)

\section{L. fumipennis Coquillett, 1901: 617.}

Diagnosis. Gena slightly higher than in L. cylindrica; eye height $2.7-3.7 \times$ genal height. Differs from all species in the L. achaeta-group by the very short-pubescent arista (as in Fig. 17). Scutum: length of bare area behind anterior declivity at most half-length of postpronotal lobe. Male genitalia very similar to L. ojibwayensis sp. n., except postgonite. Postgonite (Fig. 42) with pointed apex and rounded base, very similar to L. cylindrica but apex more slender. Allometric variation of the shape of the postgonite similar to L. cylindrica (see above) is to be
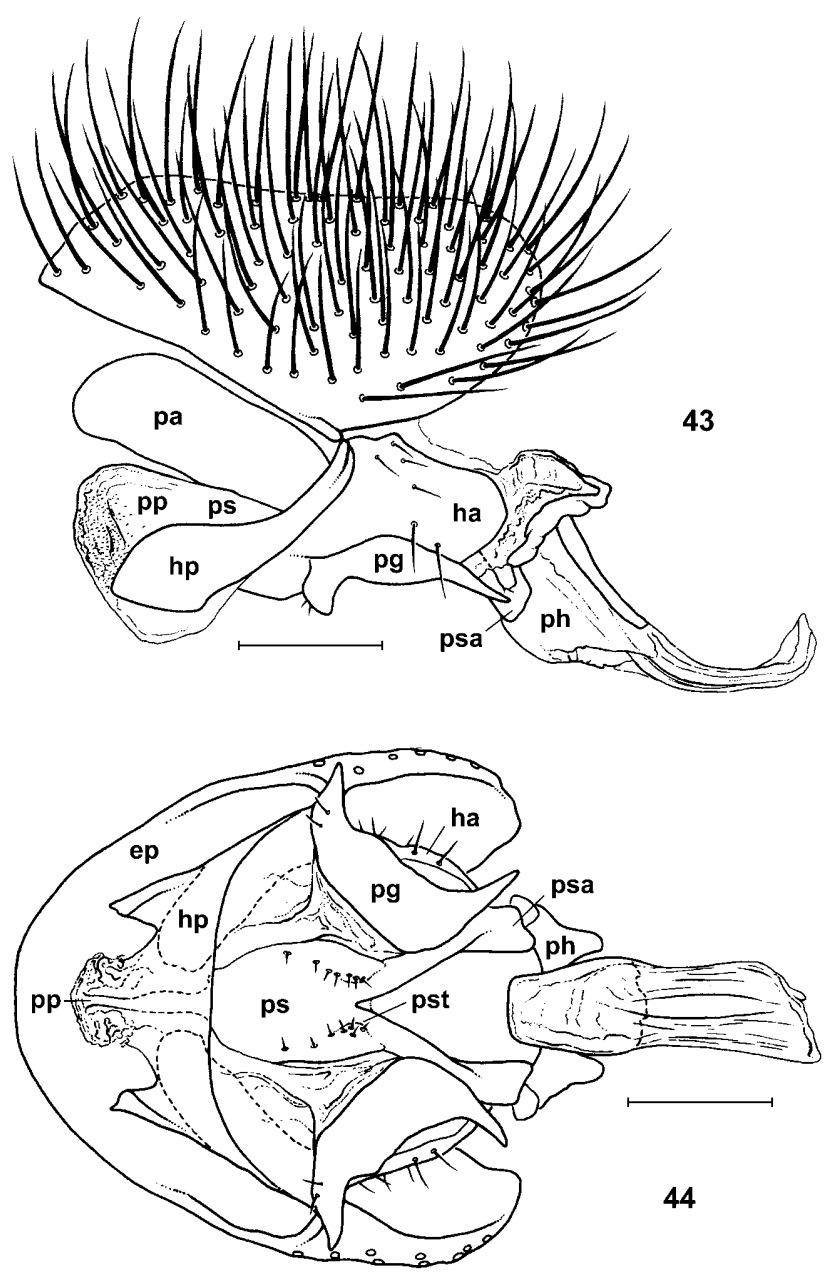

Figs 43-44. Male genitalia of Loxocera (Imantimyia) ojibwayensis sp. n. (holotype; Canada, Ontario): 43 - lateral view; 44 - ventral view. Scale $0.1 \mathrm{~mm}$. ep - epandrium, ha - hypandrial arm, hp - hypandrial plate, pa - phallapodeme, pg - postgonite, $\mathrm{ph}-$ phallus, $\mathrm{pp}-$ phallic pouch, $\mathrm{ps}-$ phallapodemic sclerite, psa - ditto, apex of posterior arm(s), pst - ditto, setulose tubercle at base of posterior arm.

expected. This phenomenon might also account for the somewhat different shape of the postgonite illustrated by Capelle (1953: Plate II, Fig. 5) (reproduced in Fig. 41). Female ovipositor similar to L. ojibwayensis sp. n. (see below).

Distribution. Prairie provinces of Canada and American midwest south to Texas and Arizona (Shewell, 1965). This species replaces $L$. cylindrica in the mid-west; the ranges of both species narrowly overlap along the eastern limit of L. fumipennis.

Material examined. Canada. Manitoba: 10, Aweme, 22.vi.1953, A.R. Brooks \& L.A. Kelton (CNCI). Saskatchewan:

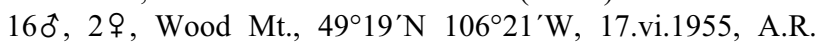
Brooks \& J.R. Vockeroth (CNCI); 120, Elbow, 23.vi.1954 and 3.-17.vi.1960, Brooks \& Wallis (CNCI); 1 \%, Swift Current, 21.vi.1937, A.R. Brooks (CNCI); $10^{\star}$, Scout Lk., 17.vi.1955, A.R. Brooks (CNCI); 30, Lisieux, $49^{\circ} 16^{\prime} \mathrm{N} 105^{\circ} 59^{\prime} \mathrm{W}$, 21.vi.1955, J.R. Vockeroth (CNCI). Alberta: 10, Brooks, 13.vi.1957, Brooks \& MacNay (CNCI); 1 t, Elkwater Pk., 11.vii.1952, L.A. Konotopetz (CNCI). USA. North Dakota: $10^{\text {t, }}$

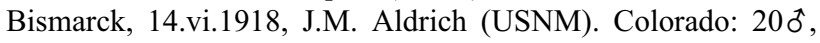
14 , $4.5 \mathrm{mi} \mathrm{N}$ Boulder, 10., 13. and 20.vi.1961, C.H. Mann \& 

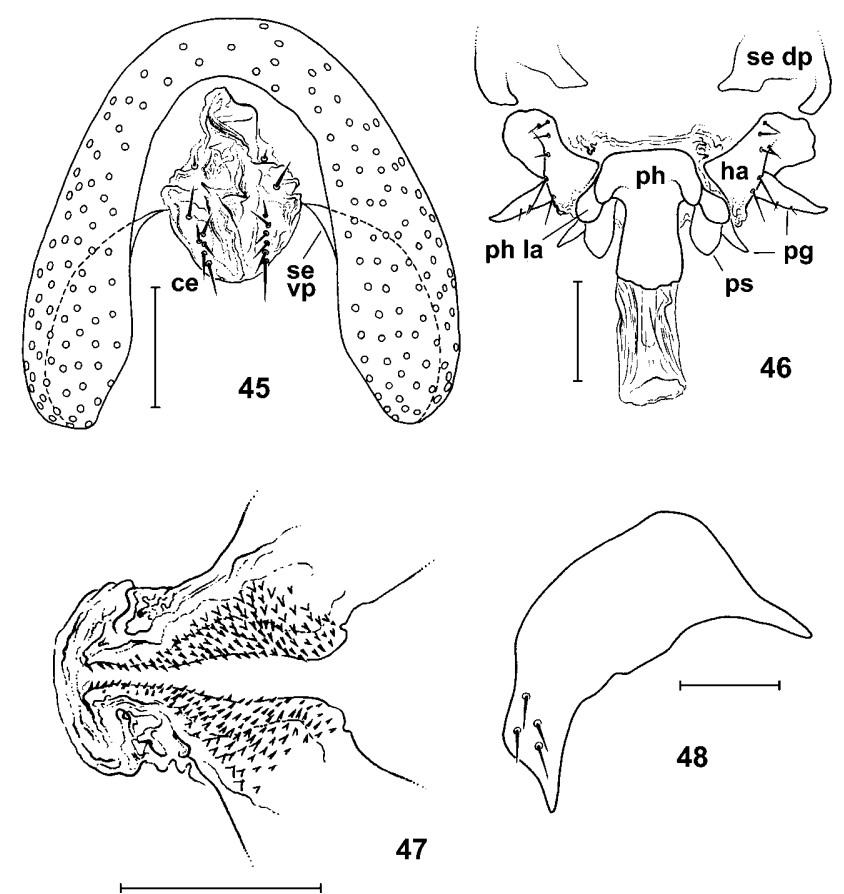

47

Figs 45-48. Male genitalia of Loxocera (Imantimyia) ojibwayensis $\mathrm{sp} . \mathrm{n}$. (Canada, Ontario): 45 - epandrium and associated structures, caudal view (holotype); 46 - phallic complex, caudal view (holotype); 47 - lateral walls of phallic pouch, ventral view (holotype); 48 - right postgonite, lateral inner view (paratype). Scale $0.05 \mathrm{~mm}$ (postgonite) and $0.1 \mathrm{~mm}$ (others). ce - cercus, ha - hypandrial arm, pg - postgonite, ph - phallus, ph la - phallus, lateral arm, ps - phallapodemic sclerite, se dp subepandrial sclerite, dorsal portion, se vp - ditto, ventral portion.

W.R.M. Mason (CNCI); 2 \%, Boulder, Valmont Butte, $5300 \mathrm{ft}$, 1.vi.1961, J.R. Stainer (CNCI); 1 ô, Longmont, $5000 \mathrm{ft}$, 3.vi.1961, B.H. Poole (CNCI); 10, "1563", collection Coquillett (USNM); Ft. Collins, 10ิ, 30.v.1902, L.A. Titus, $1 \hat{\sigma}$, 1.ix.1899, C.W. Johnson collection (USNM). Missouri: 10, Williamsville, x.-xi, J.T. Becker (CNCI). Arkansas: 1 , Granite Dells, 12.vii.1947, R.H. Beamer (SEMC). Kansas: 1 운, Lawrence, Nat. Hist. Res., 25.vi.1956, J.G. Chillcott (CNCI); 1ㅇ, Lawrence, 4.iv.1938, D.E. Hardy (SEMC); 19 , Douglas Co., 13.v.1923, W.J. Brown (CNCI); 20, 3 \% , Tonganoxie, 11.v.1940, D.E. Hardy (SEMC); 20ิ, Chanute, 29.viii.1939, R.H. Beamer (SEMC); 20ิ, Cherokee Co., 4.v.1939 and 15.v.1940, R.H. Beamer (SEMC); 1 \% Hutchinson, 7.ix.1938, D.E. Hardy (SEMC); 20ิ, 19, Menlo, 23.viii.1940, R.H. Beamer (SEMC). Texas: $30,1 \%$, Brazos Co., College Station, 26.iii. and 6.iv.1966, J.C. Schaffner \& D.M. Wood (CNCI); 60 , 4 ㅇ, Carthage, 31.iii.1968, D.M. Wood (CNCI).

\section{Loxocera ojibwayensis Buck sp. $n$.}

(Figs 19, 43-54)

Description. Body length $5.5-6.0 \mathrm{~mm}$, wing length 4.0-4.5 mm, length of antenna $1.5 \mathrm{~mm}$. Coloration similar to L. cylindrica, extent of black markings variable. Body red except: scape, first flagellomere (except sometimes extreme base), frons excluding frontal orbits (rarely ocellar triangle only), face excluding parafacials and ventromedial triangular area, occiput (rarely not), upper extreme of gena and postgena (rarely not), postpronotal
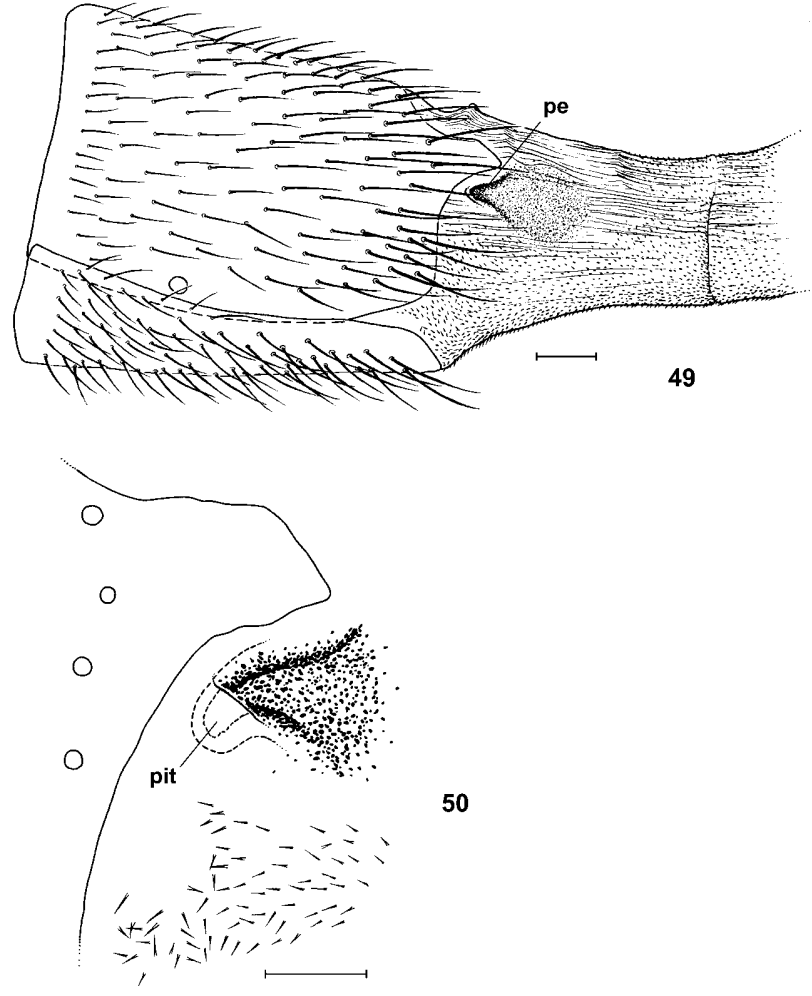

Figs 49-50. Abdominal segment 7 of female Loxocera (Imantimyia) ojibwayensis sp. n. (paratype; Canada, Ontario): $49-$ lateral view; 50 - ditto, pit region enlarged. Scale $0.1 \mathrm{~mm}$ and $0.05 \mathrm{~mm}$ (pit region). pe - pit entrance.

lobes excluding anterior surface (sometimes only narrowly along margins), anterior portion of scutum to level of posterior margin of postpronotal lobes (usually), median scutal stripe in anterior half or posterior $3 / 4$ or along whole length (rarely completely absent), sometimes a pair of free, paramedian spots at level of posterior margin of postpronotal lobes (sometimes connected to anterior black area), lower edge of notopleuron (usually), lower half or lower margin of mediotergite (rarely not), upper half of propleuron sometimes, most of tergite 1 or only median third (rarely not), female tergite and sternite 7 , and rarely female tergite 6 , black. Black body markings in some specimens medium to dark brown. Lower surface of pedicel, apical tarsal segments of all legs and sometimes apical portion of palpus darkened. Major bristles of head black. Swollen basal portion of arista reddish yellow, becoming white distally (darkened in two specimens). Gena, especially anterior half, yellowish to ivory. Haltere off-white, stem yellowish.

Head (Fig. 19). Frons not or hardly projecting beyond level of anterior eye margin, slightly transversely depressed at level of anterior third of eye. Frontal orbits silvery microtomentose in anterior half, with a row of about 10 hairs, fronto-orbital bristle not differentiated. Frontal vitta sparsely setulose in anterior half, especially near anterior margin. Ocellar triangle slightly depressed along midline, with slightly convex lateral margins, extending anteriorly about $0.85 \times$ length of frons. Ocellar bristles relatively short, length $2.0-2.5 \times$ ocellar diameter. 

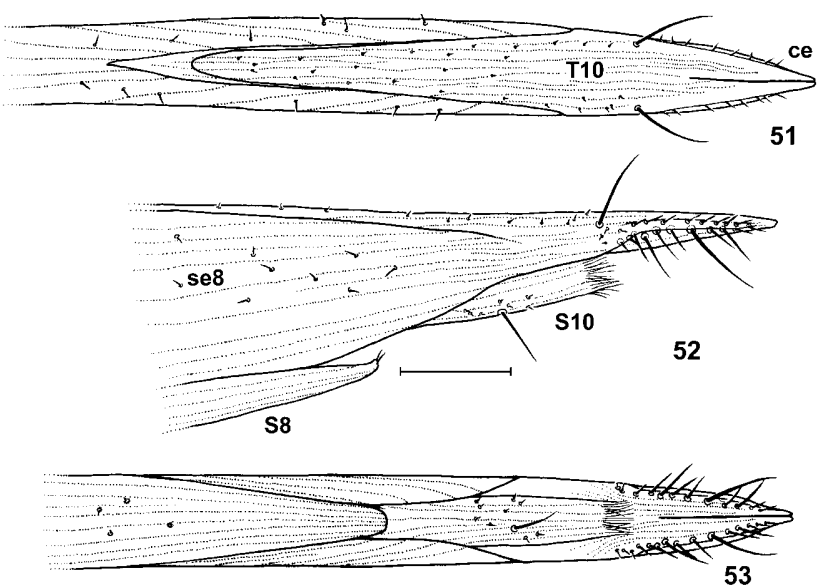

Figs 51-53. Apex of ovipositor of Loxocera (Imantimyia) ojibwayensis sp. n. (paratype; Canada, Ontario): 51 - dorsal view; 52 - lateral view; 53 - ventral view. Scale $0.1 \mathrm{~mm}$. ce cercus, se8 - segment 8; S8 - ditto, posteroventral lobe (sternite 8); S10 - sternite 10; T10 - tergite 10.

Postvertical bristles not differentiated, 2-6 postocellar hairs present. Vertical bristles short; outer vertical bristle slightly longer than inner vertical, ca. $3 \times$ as long as ocellar diameter. Face moderately slanting, below antennae in upper half with slightly elevated midline. Upper half of face with inconspicuous brownish microtomentum, lower half with more distinct silvery microtomentum, the two halves reflecting light at different angles. Microtomentum of lower face interrupted by median, triangular (dorsally tapered), bare, shining area. Parafacials narrow, at narrowest point barely as wide as swollen base of arista, with a row of setulae and with distinct silvery microtomentum. Gena with several setulae ventrally, disc very sparsely setulose, lacking silvery microtomentum. Eye large, protuberant; dorsal eye margin about level with most elevated parts of frons. Eye height 4.3-7.6× genal height. Scape slightly longer than broad (dorsal view), its length equal to maximum width of first flagellomere, with several setulae near dorsoapical margin, otherwise bare. Pedicel $1.3 \times$ as long as scape, with distinct dorsal seam, setulose. First flagellomere very long, twice as long as face, more or less parallelsided in lateral view, base hardly widened. Arista inserted close to base of first flagellomere, basal margin of socket at same level as ventroapical margin of pedicel; length of arista ca. $0.7 \times$ length of first flagellomere, with swollen basal fourth. Pubescence of swollen basal portion short, shorter than maximum diameter of arista; pubescence of slender apical portion long, longest rays twice as long as maximum diameter of arista. Palpus with scattered brownish to blackish setulae on outer and ventral surface, without outstanding bristles.

Thorax with the usual complement of bristles. Notopleural bristle poorly differentiated, brownish (not black), not much longer than surrounding hairs. Supraalar and postalar bristle well developed, always black. One prescutellar pair of dorsocentral bristles, brown to black, as long as supra-alar and postalar bristle or slightly shorter. Scutum bare anteriorly to level of posterior margin of postpronotal lobe. Hairs of scutum short, pale brown, denser along dorsocentral lines, slightly sparser between, much sparser lateral of dorsocentral lines, denser on notopleuron. Sculpture of scutum associated with density of hairing, stronger in areas that are more densely haired, smooth in bare areas. Postpronotal lobes smooth, hairs sparse, sometimes reduced to a few setulae. Scutellum with finely wrinkled disc, apical bristles ca. $0.8-1.0 \times$ as long as scutellum, preapical pair smaller, $0.4-0.6 \times$ as long as apical pair, absent in half of the specimens examined. Pleuron mostly smooth and shining; propleuron with dense, felt-like microtomentum along lower and posterior margin; posterior portion of laterotergite and lateral portions of mediotergite with sparser microtomentum. Anepisternum in posterior $3 / 5$ with short, moderately dense, upcurved brownish hair, ventrally with the usual patch of dense, pale, downcurved hair. Katepisternum with brownish hair, ventrally relatively dense and pale, dorsally sparser, central portion almost bare. Posterior spiracle with numerous long setulae along margin.

Legs haired except bare posteroventral surface of fore femur and largely bare lower surface of mid femur. Hind femur of male without ventral process. Mid tibia with one long and (1-)2 shorter ventroapical bristles, blackish or reddish except long bristle, which is black. Hind tibia with moderately developed, blackish or reddish, anteroventral, apical bristle. Hairing of tarsi becoming darker towards apex, distinctly darkened in apical 2-3 tarsomeres. Wing as in Fig. 54, membrane slightly tinged with brown, pattern somewhat variable: apical fifth of wing infuscated, sometimes just barely extending into cells $r_{1}$ anteriorly and $\mathrm{m}$ posteriorly, infuscation sometimes interrupted medially in cells $r_{2+3}$ and $r_{4+5}$. Area around posterior crossvein, last sector of $\mathrm{CuA}_{1}$ and penultimate sector of $\mathrm{M}$ (between crossveins) also infuscated, rarely area around last sector of $\mathrm{M}$ infuscated, as well, connecting apical spot with darkening around posterior crossvein. Wing veins brown in dorsal view excluding most of costa, subcosta, stem vein, $\mathrm{R}_{1}$ and $\mathrm{Rs}$, which are yellowish brown. Last sector of vein $\mathrm{M}$ with moderately strong curvature.

Preabdomen moderately slender. Syntergite 1+2 $1.2-1.3 \times$ as long as broad, laterally without conspicuously enlarged bristles in apical half of segments 1 and 2 . Tergite 1 coarsely rugose, following tergites smooth with fine transverse wrinkles. Preabdominal sternites not folded lengthwise along middle, not desclerotized medially.

Male terminalia very similar to $L$. cylindrica except postgonites. Male pregenital sclerite well defined but broadly interrupted dorsally. Epandrium of holotype darkened in ventral half. Cerci setulose (Fig. 45: ce), ventrally fused, largely membranous excluding ventral surface. Subepandrial sclerite with well-developed ventral portion (Fig. 45: se vp); dorsal portion very faintly sclerotized (Fig. 46: se dp). Phallic pouch laterally compressed (Fig. 44: pp), widening anteriorly and posteriorly; inner 
surface of pouch with minute aciculate sculpture in compressed middle portion (Fig. 47). Phallapodeme free anteriorly from phallic pouch (Fig. 43: pa). Setulae of phallapodemic sclerite few in number, posterior ones on a more or less developed protuberance near base of posterior arms (Fig. 44: pst). Apex of phallapodemic arms truncate (Figs 43, 44: psa). Lateral surface of hypandrium with a few widely scattered setulae and a small patch of microtrichia just above postgonite (Fig. 43: ha). Postgonite sickle-shaped (Fig. 48), strongly sclerotized and mostly dark brown with black apices, medial (ventral) surface with 2-4 setulae in anterior portion, lacking microtrichia. Shape of postgonite subject to slight allometric variation: in larger specimens margin next to patch of setulae more convex than in smaller specimens. Phallus T-shaped in posterior view (Fig. 46: ph), with relatively long, membranous distal portion.

Female terminalia extremely similar to L. cylindrica; no differences of taxonomic value were detected. Intersegmental membrane between segments 6-7 almost completely sclerotized (excl. pleural portions and dorsomedial emargination), sclerotization continuous with tergite and sternite. Segment 7 laterally compressed (Fig. 49), tergite subcarinate along midline, especially in anterior half. Tergite 7 on each side with short posterior extension and a small pit below it (Fig. 50); exposed (non-retractable) portion of intersegmental membrane bare and minutely longitudinally striate in anterior $2 / 3$ of dorsal surface, otherwise finely microtrichose, retractable portion of intersegmental membrane entirely microtrichose. Segment 8 (Figs 51-53) distinctly striate on whole surface, with scattered short setulae, completely devoid of microtrichia; posterior margin with deep, acute, medial emargination dorsally (Fig. 51), not clearly delimited laterally, and with a simple, narrowly rounded sternal lobe. Tergite 10 and cerci fused (Fig. 51: T10, ce). Tergite 10 dorsally with scattered, short setulae and one pair of bristles just basal of free apical portion of cerci. Sternite 10 with a few scattered setulae and 1-2 longer bristles, apex with a fringe of long felt-like microtrichia (Fig. 52, 53: S10). Cerci (Figs 51-53: ce) moderately flattened dorsoventrally, relatively long, clearly discernable even in undissected specimens. Each cercus bare dorsally, with a lateral row of short bristles that appear to arise from a small groove, and with a ventral row of longer bristles, two of which are enlarged.

Type material. Holotype $\hat{o}$ (debu01117471). Canada. Ontario: Essex Co., Windsor, Ojibway Prairie nr. Sprucewood Ave. observation point, $42^{\circ} 15^{\prime} 51^{\prime \prime} \mathrm{N}, 83^{\circ} 4^{\prime} 30^{\prime \prime} \mathrm{W}, 26 .-27$.viii. 2002, yellow pans, M. Buck \& S.M. Paiero (DEBU). Paratypes $20,14 \%$ (all DEBU). Canada, Ontario: 1 9 , (debu01117472), same data as holotype; 2 ( debu01118320, debu01118321), same data as holotype except 12.-13.ix.2002; 10, 5 우 (debu00251754 to ...759), same locality as holotype, 28.-29.vii. 2005, yellow and white pans, S.M. Paiero \& M.D. Bergeron; Windsor, Ojibway Prairie, $42^{\circ} 15^{\prime} 51^{\prime \prime} \mathrm{N}, 83^{\circ} 4^{\prime} 30^{\prime \prime} \mathrm{W}, 12 .-13$.ix. 2002, 1 ㅇ (debu00216770), yellow pans in loamy depression, 1 ㅇ (debu00216735), netted, M. Buck; 1 ㅇ (debu00253172), same locality as previous, 25.vii.2003, yellow pans, S.M. Paiero; 1 \%, Windsor, Ojibway Prairie Reserve, 11.vii.1980, K.N. Barber; Windsor, $\sim 1.5$ km S Ojibway Prairie, $42^{\circ} 13^{\prime} 34^{\prime \prime} \mathrm{N}$, $83^{\circ} 4^{\prime} 27^{\prime \prime} \mathrm{W}$, forest-prairie edge, 1 ơ $^{\circ}$ debu01118304), 18-31.vii.

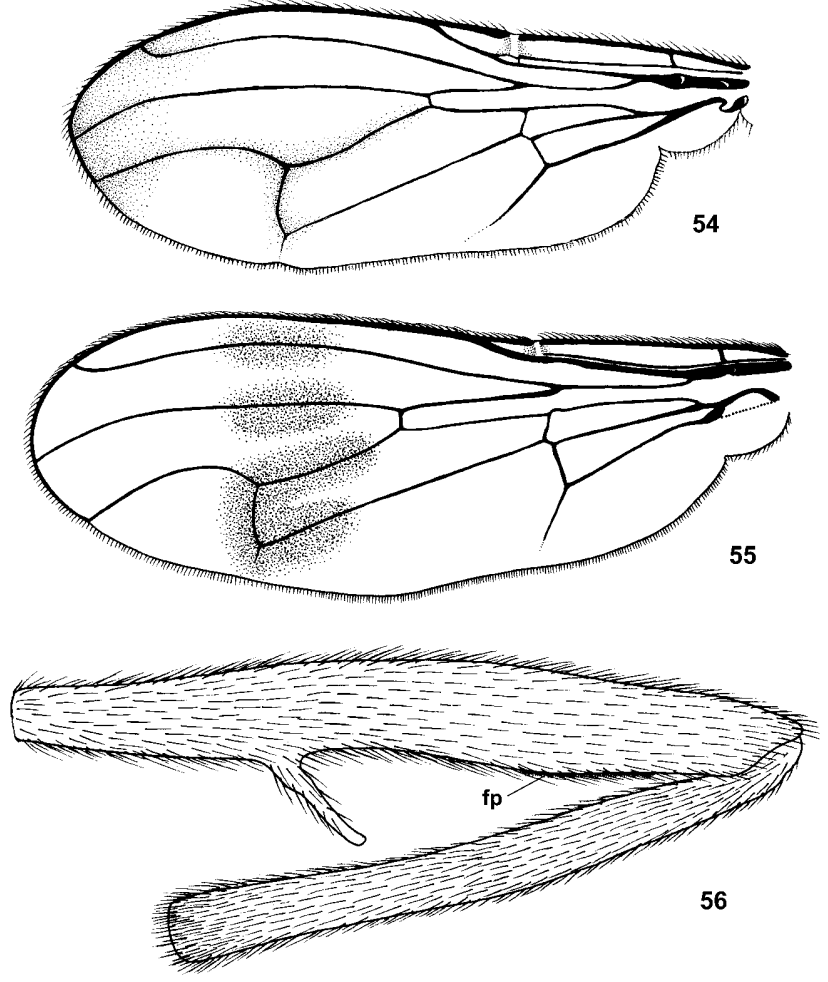

Figs 54-56. External characters of Loxocera (Imantimyia) achaeta-group. L. ojibwayensis sp. n.: 54 - left wing (paratype; Canada, Ontario). L. ignyodactyla sp. n.: 55 - left wing (paratype; Costa Rica, Puntarenas); 56 - male hind femur and tibia, posterior view (holotype). fp - patch of felt-like microtomentum.

2001, 1 우 (debu01113897), 1.-22.ix.2001, S.M. Paiero, 1 우 (debu01109235), 1.-19.viii.2001, P. Pratt, all in malaise trap.

Etymology. The name refers to the type locality, Ojibway Prairie in Windsor, Ontario.

Distribution. At present only known from extreme southwestern Ontario in Canada.

Relationships. This species shows similarities with both the Palaearctic L. achaeta / L. lutulenta / L. nigrifrons and the Nearctic L. cylindrica / L. fumipennis. Most remarkably, the postgonite of the new species has the same two-pronged shape as the three Palaearctic species (Shatalkin, 1989: Pl. 3, Fig. 2; Iwasa, 1992: Fig. 21). Loxocera ojibwayensis sp. n., L. lutulenta and L. nigrifrons also share the large bare anterior area of the scutum (L. achaeta not examined). The three Nearctic species, on the other hand, possess a notopleural and one pair of dorsocentral bristles, which are reportedly absent in $L$. achaeta and L. lutulenta (Iwasa, 1992). However, a male of L. lutulenta (Japan: Mt. Atago nr. Kyoto, CNCI) examined by us has well developed dorsocentral bristles and a pale, inconspicuous notopleural bristle but otherwise agrees well with the original description (Iwasa, 1992). Variation in the development of dorsocentral bristles also occurs in L. aristata (see Greve \& Skartveit, 2001) so the taxonomic importance of this character should not be overestimated. 


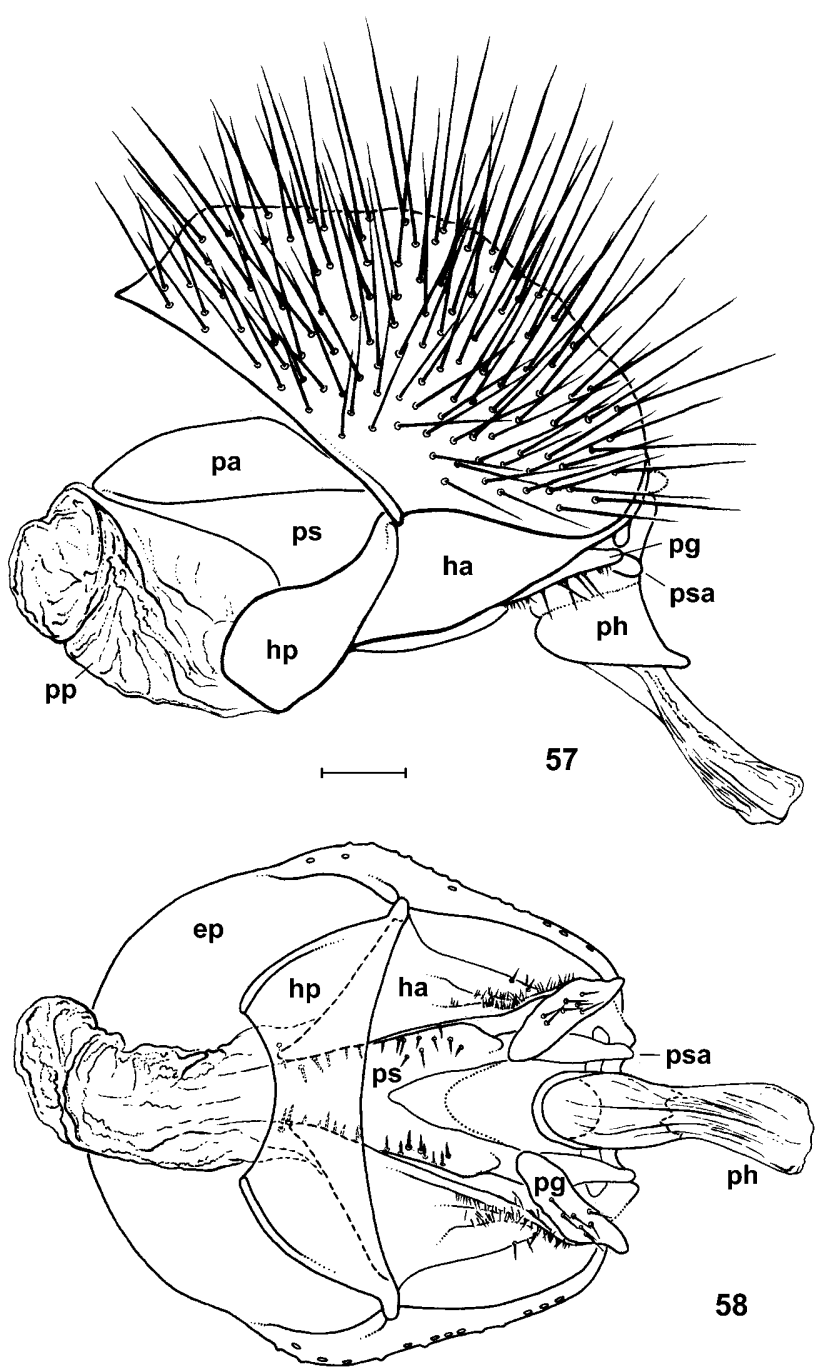

Figs 57-58. Male genitalia of Loxocera (Imantimyia) ignyodactyla sp. n. (holotype; Costa Rica, Puntarenas): 57 - lateral view; 58 - ventral view. Scale $0.1 \mathrm{~mm}$. ha - hypandrial arm, hp - hypandrial plate, pa - phallapodeme, pg - postgonite, ph phallus, $\mathrm{pp}$ - phallic pouch, $\mathrm{ps}$ - phallapodemic sclerite, psa ditto, apex of posterior arm(s).

\section{Loxocera ignyodactyla Buck sp. $\mathbf{n}$.}

(Figs 5, 20, 55-65)

Description. Largest species of the subgenus and one of the largest species in the genus, body length $12 \mathrm{~mm}$, wing length $8 \mathrm{~mm}$, length of antenna $3 \mathrm{~mm}$. Body red except: Scape, first flagellomere except extreme base, ocellar prominence and small area right behind posterior ocelli, postpronotal lobes excluding margins and anterior surface, black. Major bristles of head and thorax also black. Palpus blackish in male, hardly infuscated in female (difference probably due to individual variability, not sexual dimorphism). Pedicel on outer surface and ventrally, first flagellomere basal of arista, dark reddish. Swollen basal portion of arista reddish yellow, becoming white distally. Face and gena slightly yellowish red. Haltere yellowish.

Head (Figs 5, 20). Frons strongly projecting beyond level of anterior eye margin (much more than in Nearctic
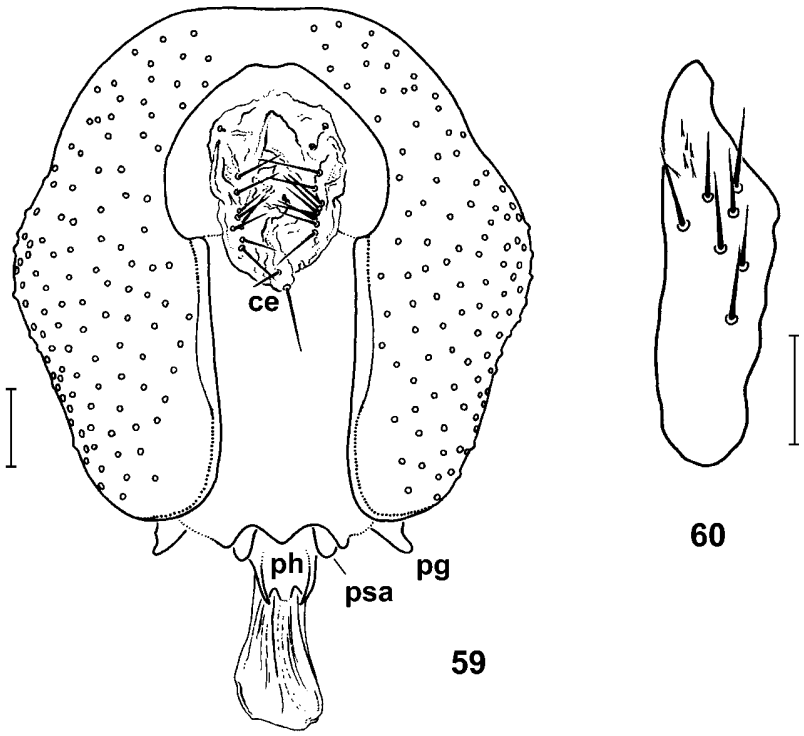

60



Figs 59-61. Male genitalia of Loxocera (Imantimyia) ignyodactyla sp. n. (holotype; Costa Rica, Puntarenas): 59 - epandrium and associated structures, caudal view; 60 - postgonite, lateral inner view; 61 - phallic complex, caudal view. Scale $0.05 \mathrm{~mm}$ (postgonite) and $0.1 \mathrm{~mm}$ (others). ce - cercus, ha hypandrial arm, hp - hypandrial plate, pg - postgonite, ph phallus, ps - phallapodemic sclerite, psa - ditto, apex of posterior $\operatorname{arm}(\mathrm{s})$.

species), slightly transversely depressed at level of anterior third of eye. Frontal orbits with a row of about 15 hairs, last hair enlarged, ca. twice as long as previous ones, forming a small fronto-orbital bristle. Frontal vitta sparsely setulose in anterior half, especially near anterior margin. Ocellar triangle slender and very pointed, with slightly concave lateral margins, extending anteriorly about halfway between level of anterior margin of eye and anterior margin of frons. Ocellar bristles moderately developed, length ca. $3 \times$ ocellar diameter. Postvertical bristles not differentiated, 3-7 postocellar hairs present. Vertical bristles relatively short; inner vertical bristle slightly longer than outer vertical, ca. $4 \times$ as long as ocellar diameter. Face strongly slanting, with short, delicate median carina at level of antennal base and slightly below. Parafacials narrow, at narrowest point barely as wide as swollen base of arista, with a row of setulae and 
with weak silvery microtomentum. Gena swollen, with several stronger setulae ventrally, disc very sparsely setulose, lacking silvery microtomentum. Eye large, protuberant; dorsal eye margin projecting slightly above level of frons. Eye height 3.3-3.4× genal height. Scape slightly longer than broad (dorsal view), its length equal to maximum width of first flagellomere, with several setulae near dorsoapical margin, otherwise bare. Pedicel slightly longer than scape, with distinct dorsal seam, setulose. First flagellomere very long, twice as long as face, its diameter slightly increasing towards apex (lateral view), base hardly widened. Arista inserted close to base of first flagellomere, basal margin of socket removed from (level of) ventroapical margin of pedicel by $1.0-1.5 \times$ ocellar diameter; length of arista ca. $0.8 \times$ length of first flagellomere, with swollen basal fourth. Pubescence of swollen basal portion short, shorter than maximum diameter of arista; pubescence of slender apical portion long, longest rays twice as long as maximum diameter of arista. Palpus with scattered blackish setulae on outer and ventral surface, without outstanding bristles.

Thorax with the usual complement of bristles. Notopleural bristle slightly over half as long as the supraalar and postalar bristle. One prescutellar pair of dorsocentral bristles, $1.3-1.4 \times$ as long as supra-alar and postalar bristles. Scutum with rough surface sculpture in haired region, smooth in bare anterior region. Scutum bare up to level of anterior third of postpronotal lobe, otherwise uniformly setulose. Hairing of scutum short and dense, mostly black, reddish in notopleural region, not arranged in rows. Postpronotal lobes smooth, hairing much sparser than on scutum. Scutellum with finely wrinkled disc, apical bristles ca. $1.4 \times$ as long as scutellum, preapical pair small, only ca. $0.3 \times$ as long as apical pair. Pleuron mostly smooth and shining; propleuron with dense, felt-like microtomentum along lower and posterior margin; posterior portion of laterotergite and lateral portions of mediotergite with sparser microtomentum. Anepisternum posteriorly and dorsally with short, moderately dense, upcurved reddish hair, in posteroventral corner with the usual patch of dense, pale, downcurved hair. Katepisternum with reddish hair, ventrally relatively dense, dorsally sparser, central portion almost bare. Posterior spiracle with numerous long setulae along margin.

Legs more or less uniformly haired except bare posteroventral surface of fore femur and largely bare lower surface of mid femur. Hind femur of male with distinct posteroventral process before middle (Fig. 56). Mid tibia with one long and 2-3 shorter ventroapical bristles, mostly reddish except long bristle, which is black in one of the two specimens. Hind tibia with moderately developed, reddish, anteroventral apical bristle. Hairing of tarsi becoming darker towards apex, distinctly darkened in apical three tarsomeres. Wing (Fig. 55) distinctly yellowish, with moderately developed dark band at level of posterior crossvein; band more or less interrupted along centre of cells $\mathrm{r}_{2+3}, \mathrm{r}_{4+5}$ and $\mathrm{dm}$. Wing veins mostly yellowish, brown in banded part of wing. Last sector of vein $\mathrm{M}$ with unusually strong curvature.

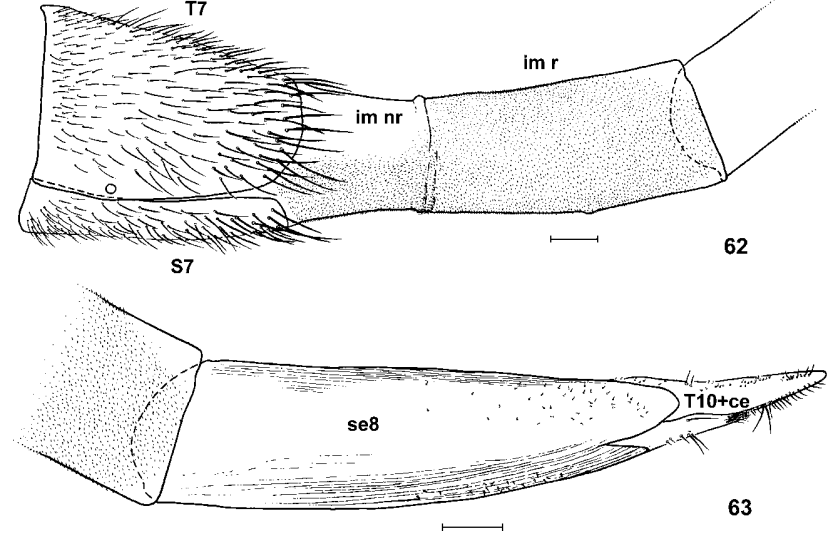

Figs 62-63. Ovipositor of Loxocera (Imantimyia) ignyodactyla sp. n. (paratype; Costa Rica, Puntarenas), lateral view: $62-$ segment 7; 63 - segment 8 and onward. Scale $0.2 \mathrm{~mm}$. ce - cercus, im $\mathrm{nr}$ - intersegmental membrane, non-retractable portion, im $\mathrm{r}$ - ditto, retractable portion, se 8 - segment $8, \mathrm{~S}-$ sternite, $\mathrm{T}$ - tergite.

Preabdomen slender. Syntergite $1+2$ ca. twice as long as broad (ratio influenced by shrinkage from drying), laterally with conspicuously enlarged bristles in apical halves of segments 1 and 2, on latter almost erect and nearly as long as width of segment at level of insertion (in air-dried specimens). Abdominal tergites smooth, with very fine, evenly spaced, transverse wrinkles; tergite 1 hardly with coarser sculpture.

Male pregenital sclerite weakly sclerotized and hardly discernible but apparently forming a complete dorsal arch between spiracles 7. Epandrium evenly setose (Fig. 57). Cerci setulose (Fig. 59), ventrally more or less fused, largely membranous excluding ventral surface. Subepandrial sclerite with well developed broad-elliptical ventral portion; extending from lower margin of epandrium to lower margin of cerci along posterior margin of epandrium; dorsal portion completely desclerotized, undifferentiated. Phallic pouch large, curved towards left side of body (Fig. 58: pp), not laterally compressed as in Nearctic species of $L$. achaeta-group; inner surface of pouch with minute aciculate sculpture posteriorly, finely denticulate near middle (denticles with broadly rounded apices), simple anteriorly. Phallapodeme moderately developed, connected to phallapodemic sclerite through its entire length, anterior end not separated from phallic pouch (Fig. 57: pa). Phallapodemic sclerite with relatively numerous, scattered setulae on ventral surface (Fig. 58: ps), lacking setulose protuberances at base of phallapodemic arms; the latter with more slender apex (Figs 57-59: psa) than in L. ojibwayensis sp. n. Lateral surface of hypandrium extensively microtrichose and with a few setulae above postgonites (Fig. 58, 61: ha). Postgonite elongate (Fig. 60), with rounded base and pointed apex, medial (ventral) surface with seven setulae and in apical third with a few microtrichia, moderately sclerotized and rather pale brown throughout, not dark brown to black as in Nearctic species. Phallus T-shaped in posterior view 

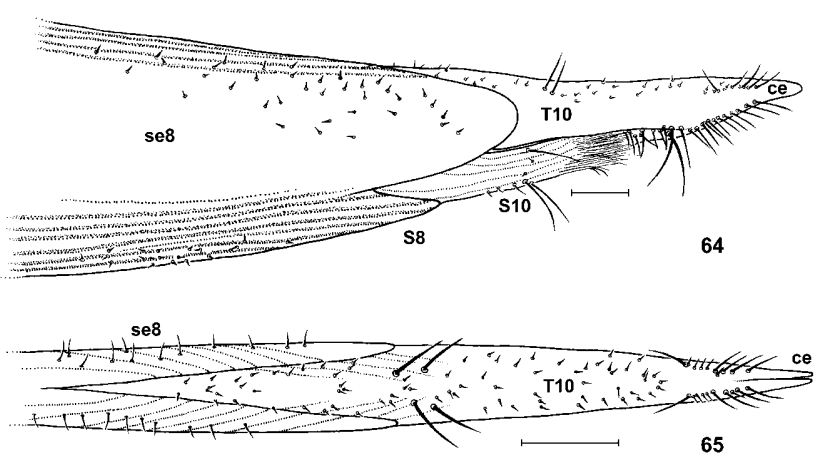

Figs 64-65. Apex of ovipositor of Loxocera (Imantimyia) ignyodactyla sp. n. (paratype; Costa Rica, Puntarenas): 64 - lateral view; 65 - dorsal view. Scale $0.1 \mathrm{~mm}$. ce - cercus, se 8 segment 8 , S8 - ditto, posteroventral lobe (sternite 8), S10 sternite $10, \mathrm{~T} 10$ - tergite 10 .

(Fig. 61: ph), with broadly expanded lateral arms, and relatively long, membranous distal portion.

Female terminalia. Intersegmental membrane between segments 6 and 7 long, sclerotized behind sternite 6 and laterally behind tergite 6 . Segment 7 laterally compressed (Fig. 62) but tergite not carinate medially. Tergite 7 lacking paired, posterior extensions and pair of small pits. Exposed, non-retractable portion of intersegmental membrane (Fig. 62: im nr) with bare, minutely longitudinally striate dorsal surface and finely microtrichose ventral surface; retractable portion (Fig. 62: im r) entirely microtrichose. Segment 8 distinctly striate dorsally and ventrally (Fig. 63: se8), smooth and sclerotized laterally, surface with scattered short setulae; posterior margin with deep, triangular incision dorsally (Fig. 65), produced into a pair of broad rounded lobes laterally, and with a simple, narrowly rounded sternal lobe (Fig. 64: S8). Tergite 10 and cerci fused (Fig. 65: T10, ce), with two pairs of bristles near base and two longitudinal rows of bristles near apex, otherwise with scattered, very short and fine setulae. Sternite 10 with a few long bristles and few scattered setulae, posteriorly terminating in a fringe of long felt-like microtrichia (Fig. 64: S10). Cerci not dorsoventrally flattened, fused to each other over most of their length except near apex (appearing completely fused in undissected specimens); ventral surface of tergite $10+$ cerci with a longitudinal row of bristles on each side (Fig. 64).

Type material. Holotype $\widehat{\delta}$, Costa Rica: Prov. Puntarenas, $\mathrm{P}$ [arque] Int[ernacional] La Amistad, de [from] Cerro Becón a [to] Tres Collinas, 2124 m, 17.iv.2002, M. Alfaro, libre, L S 343750_565700, \#69143 (INBC). Paratype + , Costa Rica: Prov. Puntarenas, Sabalito, Cerro Quijada del Diablo, $1950 \mathrm{~m}$, 11.vi.2000, M. Alfaro, manual, L_S_317400_600800, \#59062 (INBC).

Etymology. The name is a latinized compound Greek adjective and refers to the finger-like ventral process of the male hind femur (Gr. ignya: part of leg behind thigh and knee, ham; Gr. daktylos: finger).

Distribution. Only known from Puntarenas Province in Costa Rica at elevations around $2000 \mathrm{~m}$.
Relationships. Despite significant differences this species is best placed within the mainly Holarctic L. achaetagroup (see phylogeny of Imantimyia above). It preserves several plesiomorphic features that have been lost in the Holarctic species (see phylogenetic analysis of Imantimyia species groups above) and represents the most basal member of its group.

\section{Taxonomic treatment: eggs}

In order to allow comparisons between all available subgenera and species groups of Loxocera, three species representing Old World-restricted groups were included in the following treatment: $L$. (L.) hoffmannseggi, $L$. $(L$. aristata, L. (Imantimyia) albiseta. Besides describing the eggs of Loxocera, we include a description and discussion of the egg of Psila (Asiopsila) decorata, justifying the removal of Asiopsila from Loxocera (see above).

Generic diagnosis (based on the species included in the key below). Eggs roughly cylindrical, sometimes very slightly curved or with straight lower (?) and arched upper (?) surface, length $0.95-2.3 \mathrm{~mm}$, width $0.20-0.33$ $\mathrm{mm}$, slightly tapered towards both ends, which are rounded or narrowly truncate; micropylar end always more obtuse or more broadly truncate than posterior end. Chorion with very finely to very coarsely granular texture. Surface either with linear polygonal reticulation or with fine, close-set, longitudinal ridges connected by variably developed transverse ridges or with a combination of both. Surface in some species partially plain (without reticulation or ridging). Texture of chorion usually becoming coarser at both poles, appearing microporose or microreticulate, increasing in size to small or large pores. Micropyle located in centre of poorly to sharply defined, flat to deeply depressed, central area, which is of finer texture than surrounding area.

\section{Key to known eggs of Loxocera s. 1.}

Note: For a key to Psilidae genera see Buck (in press).

1 Reticulation of egg surface coarse (Figs 73, 76, 77, 85), at most in small areas fine and linear; reticulation raised (sometimes developed as longitudinal ridges, e.g. Fig. 76), ridges prominent and well-defined or weakly developed as very low, rounded ripples................ 2

- Reticulation fine and linear (Figs $68,78,83,84,86$ ), in certain areas hardly noticeable to completely absent; reticulation never raised, not forming a ripple structure. . . . . . 6

2 Micropylar pole broadly truncate (Fig. 69), micropylar depression deep and funnel-like, surrounding rim with small teeth (Fig. 70). Posterior pole rounded (Palaearctic). . . . . . . . $\ldots \ldots \ldots \ldots \ldots \ldots \ldots \ldots \ldots . \ldots \ldots \ldots \ldots$. (L.) hoffmannseggi

- Micropylar pole broadly truncate to rounded, micropylar depression shallow and often indistinct, surrounding rim never toothed. Posterior pole truncate or rounded. ...... 3

3 Egg truncate at both poles (Fig. 72). Micropylar area (Fig. 71) with scattered pores, central poreless area around micropyle large (Palaearctic)............... L. (L.) albiseta

- At least posterior pole of egg rounded. Micropylar elevation with close-set pores, central poreless area around micropyle small to medium-sized. . . . . . . . . . . . . . . . . 4 
4 Ventral(?) surface of egg with linear polygonal reticulation that is not raised above surface (Fig. 86), elsewhere with raised longitudinal ridges connected by short transverse ridges (Fig. 85). Micropylar pole (Fig. 87) and posterior pole with small pores that increase in size toward centre (Nearctic)................. L. (I.) ojibwayensis sp. n. Egg surface with raised ridges or raised reticulation on whole surface (Figs 76, 77). Micropylar pole and posterior pole with large pores of more or less uniform size (Fig. 74). .

5 Egg surface with broader longitudinal ridges connected by few, very narrow, inconspicuous, transverse ridges (Fig. 76); interspaces without circular spots (Nearctic)......... .............................. (I.) collaris

- Egg surface polygonally reticulated (Fig. 77); width of ridges uniform regardless of orientation; each polygon with (0-)1-2 circular or elliptic spots (Nearctic). . L. (I.) microps

6 Posterior pole of egg with moderately coarse granular texture, granulation not coarser than elsewhere on surface (Neotropical)............... L. (I.) ignyodactyla sp. n. Posterior pole of egg with very coarse granular texture (appearing microporose) or with small pores, texture much coarser than elsewhere on surface. . . . . . . . . . 7

7 Micropylar pole with ill-defined, very coarsely granular central area (Fig. 66). Granulation otherwise uniform over whole surface (Fig. 68). Reticulation weakly developed on two opposite sides (Fig. 68), absent on the other two sides (Palaearctic)...................... (L.) aristata - Micropylar pole with sharply defined, smooth (non-granular) central area (Fig. 79). Granulation of surface coarser in reticulated than in unreticulated areas. . . . . . . 8

8 Reticulation distinct in two broad bands (each ca. 8 polygons wide) on opposite sides, elsewhere weaker to absent (Nearctic)....................... (I.) cylindrica

- Reticulation distinct in two narrow bands (each ca. 3-4 polygons wide) on opposite sides (Fig. 78), elsewhere very faint to absent (Nearctic). . . . . . . . . . L. (I.) fumipennis

\section{Loxocera (L.) aristata (Panzer, 1801)}

(Figs 66-68)

Description. Egg (Fig. 67) about as long as abdominal segments 3-4 combined (length ca. $1.35 \mathrm{~mm}$, width ca. $0.25 \mathrm{~mm}$ ); micropylar pole minutely truncate, micropylar area slightly depressed below rim; posterior pole rounded. Two opposite sides very faintly reticulated with somewhat irregular polygons (Fig. 68); remaining two sides plain. Reticulation linear and not raised above surface level. Chorion with uniform, slightly coarse, granular (microporose?) texture. Granular texture becoming increasingly coarser near both poles; growing into small, close-set pores that increase in size towards centre. Micropylar pole (Fig. 66) with ill-defined, very coarsely granular central area lacking pores, with micropyle in centre.

Material examined. Sweden: 11 eggs from one female, Värmland, Ekshärad, 23.vii.1960, W.R.M. Mason (CNCI).

\section{Loxocera (L.) hoffmannseggi (Meigen, 1826)}

(Figs 69, 70)

Description. Egg (Fig. 70) about $0.75 \times$ as long as abdominal segments 3-4 combined (length 1.70-1.85 $\mathrm{mm}$, width $0.33-0.35 \mathrm{~mm}$ ); micropylar pole broadly truncate (Fig. 69) micropylar area deeply depressed and sur-

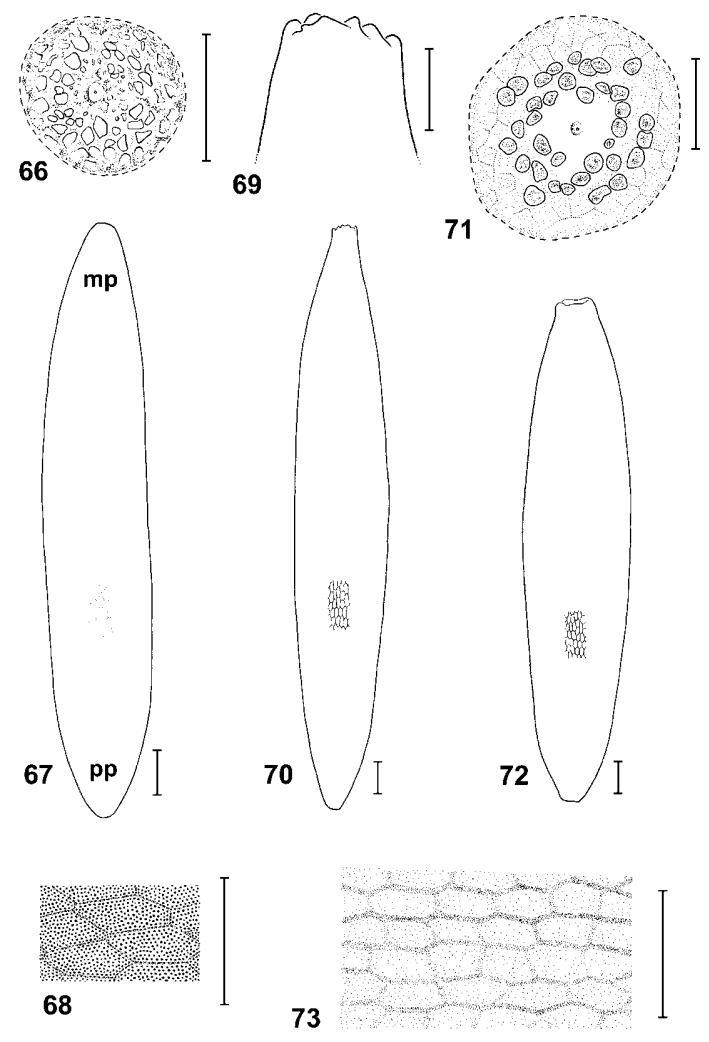

Figs 66-73. Eggs of Loxocera s. str. and L. (Imantimyia). L. (L.) aristata (Sweden, Värmland): 66 - micropylar area, frontal view; 67 - egg, lateral view; 68 - chorion, lateral surface, fine structure. L. (L.) hoffmannseggi (Germany, Bayern): 69 micropylar pole, lateral view; 70 - egg, lateral view. L. (Imantimyia) albiseta (England, Devon): 71 - micropylar area, frontal view; 72 - egg, lateral view; 73 - chorion, lateral surface, fine structure. Scale $0.1 \mathrm{~mm}$ (egg, total) and $0.05 \mathrm{~mm}$ (others). $\mathrm{mp}-$ micropylar pole, $\mathrm{pp}$ - posterior pole.

rounded by a circle of small, irregular teeth; posterior pole rounded. Chorion relatively thick, with very fine, uniform, granular texture. Surface reticulated with rows of somewhat irregular polygons; reticulation very faint to practically absent in two narrow longitudinal bands (width of these bands ca. five polygons); bands separated by an angle of roughly $130-140^{\circ}$ in cross section. Rows of polygons numbering ca. 90 across circumference at level of greatest diameter; polygons becoming shorter near posterior pole. Reticulation slightly raised above surface level (surface not distinctly ridged). Micropylar depression with coarse irregular pores ("spongy") except bottom around micropyle, which is completely smooth.

Material examined. Germany: five eggs from one female, Oberbayern, Distr. Fürstenfeldbruck, Schöngeising, Pointl, 550 m, 17.viii.1991, W. Schacht (ZSMC).

\section{Loxocera (Imantimyia) albiseta (Schrank, 1803)}

(L. albiseta-group)

(Figs 71-73)

Description. Egg (Fig. 72) about as long as abdominal segments 3-4 combined (length 1.4-1.5 mm, width ca. $0.3 \mathrm{~mm}$ ); micropylar pole distinctly truncate, surface of truncation slightly depressed below rim; posterior pole 

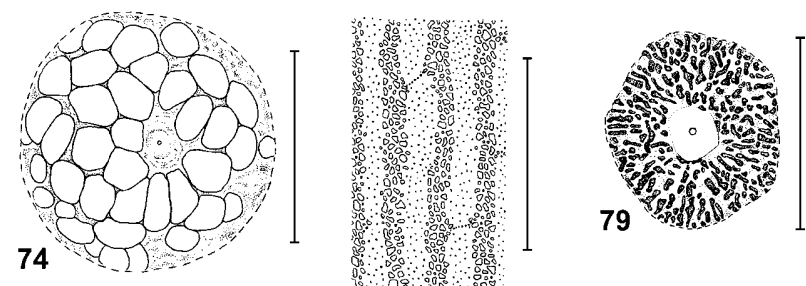

76

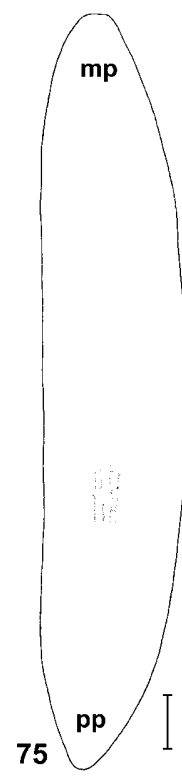

Figs 74-80. Eggs of Loxocera (Imantimyia). L. (I.) collaris (USA, Tennessee): 74 - micropylar area, frontal view; 75 - egg, lateral view; 76 - chorion, lateral surface, fine structure. $L$. (I.) microps (Canada, British Columbia): 77 - chorion, lateral surface, fine structure. L. (I.) fumipennis (USA, Texas): 78 - chorion, lateral surface, fine structure; 79 - micropylar area, frontal view; $80-$ egg, lateral view. Scale $0.1 \mathrm{~mm}$ (egg, total) and 0.05 $\mathrm{mm}$ (others). $\mathrm{mp}$ - micropylar pole, $\mathrm{pp}$ - posterior pole.

with small, even truncation. Chorion relatively thick, with very fine, uniform, granular texture. Entire surface reticulated with rows of somewhat irregular polygons (Fig. 73); polygons becoming shorter near poles, especially near posterior pole; polygons with $0-1(-2)$ very faint, circular spots of slightly coarser granular texture; rows of polygons numbering ca. 70 across circumference at level of greatest diameter. Reticulation slightly raised above surface level (surface not distinctly ridged). Micropylar truncation (Fig. 71) with scattered, roughly circular pores (aeropyles?) separated by smooth interspaces; central area around micropyle lacking pores. Posterior truncation also with pores, but pores separated by mostly very small, ridge-like interspaces and present in central area, as well.

Material examined. Great Britain: 16 eggs from one female, Devon, Paignton, Clennon Valley, 8.viii.1960, J.R. Vockeroth (CNCI).

\section{Loxocera (Imantimyia) collaris Loew, 1869}

(L. fulviventris-group)

(Figs 74-76)
Description. Egg (Fig. 75) about as long as abdominal segments 3-4 combined (length $0.95-1.00 \mathrm{~mm}$, width ca. $0.20 \mathrm{~mm}$ ); micropylar pole more obtusely rounded than posterior pole. Surface covered with fine, close-set, longitudinal ridges that are connected by short, very faintly indicated, transverse ridges (Fig. 76); transverse ridges more prominent near poles, especially near micropylar pole. Number of ridges totalling ca. 55 across circumference at level of greatest diameter. Chorion with extremely fine, granular texture between ridges; ridges itself fairly coarsely granular. Both poles completely occupied by large pores that are separated by thin lamellar ridges, size of pores not increasing toward centre; micropyle in small circular depression in centre of micropylar pole (Fig. 74).

Material examined. USA: eight eggs from one female, Tennessee, Great Smoky Mts Natl. Pk., Collins Gap, 5,700 ft, 22.viii.1957, J.G. Chillcott (CNCI).

\section{Loxocera (Imantimyia) microps Melander, 1920 \\ (L. fulviventris-group) \\ (Fig. 77)}

Description. Egg about as long as abdominal segments 3-4 combined (length ca. $1.1 \mathrm{~mm}$, width ca. $0.20 \mathrm{~mm}$ ); micropylar pole more obtusely rounded than posterior pole. Entire surface reticulated with somewhat irregular polygons that are not arranged in distinct rows (Fig. 77); polygons becoming shorter near poles; number of polygons totalling ca. 55 across circumference at level of greatest diameter; reticulation slightly raised above surface. Chorion with extremely fine, granular texture between ridges; slightly coarser on ridges, with a larger spot at each intersection; centre of each polygon with (0-)1-2 circular to elliptic, slightly coarser granular areas. Micropylar pole and posterior pole similar to $L$. collaris but pores slightly smaller.

Material examined. Canada: three eggs from one female, British Columbia, Lisadele Lk., 4,000 ft, $58^{\circ} 41^{\prime} \mathrm{N} 133^{\circ} 4^{\prime} \mathrm{W}$, 7.viii.1960, R. Pilfrey (CNCI).

\section{Loxocera (Imantimyia) cylindrica Say, 1823 \\ (L. achaeta-group)}

Description. Egg slightly longer than abdominal segments 3-4 combined (length ca. $1.25 \mathrm{~mm}$, width ca. 0.20 $\mathrm{mm}$ ), both poles rounded, micropylar pole more obtuse. Surface on two opposite sides with distinct, linear, somewhat irregular polygonal reticulation (area of distinct reticulation ca. 8 polygons wide), third side with similar but fainter reticulation, fourth side almost plain, with extremely faint reticulation; polygons shorter near poles and reticulation distinct around whole circumference. Number of rows of polygons totalling ca. 35 across circumference at level of greatest diameter. Chorion with moderately coarse, granular texture in areas with distinct reticulation; granulation very fine in weakly reticulated areas. Micropylar pole very coarsely granular, appearing irregularly microporose, with sharply defined, circular, smooth, central area bearing micropyle in centre. Posterior pole very coarsely granular, appearing microporose. 
Material examined. Canada: four eggs from one female, Newfoundland, St. John's, Agricultural Experiment Station, 26.vii.1967, J.F. McAlpine (CNCI).

\section{Loxocera (Imantimyia) fumipennis Coquillett, 1901 \\ (L. achaeta-group)}

(Figs 78-80)

Description. Egg (Fig. 80) long and slender, slightly longer than abdominal segments 3-5 combined (length $1.45-1.55 \mathrm{~mm}$, width ca. $0.20 \mathrm{~mm}$ ), very slightly curved or with straight lower (?) and arched upper (?) surface; micropylar pole narrowly subtruncate, posterior pole rounded. Concave (lower?) surface coarsely granular, lacking reticulation; arched (upper?) surface with very faint polygonal reticulation, granulation very coarse, appearing microporose, diameter of "micropores" greater than lines delimiting polygons. Surface on two opposite sides with narrow band of distinct, linear, somewhat irregular polygonal reticulation (each band only 3-4 polygons wide) (Fig. 78), third side with similar but fainter reticulation, fourth side almost plain, with extremely faint reticulation; polygons shorter near poles. Micropylar pole (Fig. 79) with very coarse irregular, dense granulation; central area surrounded by a slightly irregular ring of 10-12 small, ill-defined pore-like structures (aeropyles?); central area well defined, circular, smooth, bearing micropyle in centre. Posterior pole coarsely granular, appearing microporose.

Material examined. USA: five eggs from one female, Texas, Panola Co., Carthage, 31.iii.1968, D.M. Wood (CNCI).

\section{Loxocera (Imantimyia) ojibwayensis sp. $\mathbf{n}$.}

(L. achaeta-group)

(Figs 85-88)

Description. Egg (Fig. 88) long and slender, as long as abdominal segments 3-5 combined (length ca. $1.6 \mathrm{~mm}$, width ca. $0.25 \mathrm{~mm}$ ); micropylar pole with small truncation, posterior pole narrowly rounded. Chorion with very fine, uniform, granular texture. Surface (excluding ventral side) covered with fine, close-set, longitudinal ridges connected by very short, narrow, transverse ridges (Fig. 85). Lower surface finely reticulated with somewhat irregular, elongate (mostly hexagonal) polygons (Fig. 86), which become gradually less elongate at both poles; reticulation not raised above surface level. Number of rows of polygons on lower surface plus number of ridges of remaining surface totalling ca. 85 across circumference at level of greatest diameter. Micropylar pole (Fig. 87) with close-set pores of variable size (mostly large), except in central area, which is depressed and bears micropyle in centre. Posterior pole coarsely granular with small close-set pores in centre.

Material examined. Canada: two eggs from female paratype debu01117472 (full data above).

\section{Loxocera (Imantimyia) ignyodactyla sp. $\mathbf{n}$. (L. achaeta-group) \\ (Figs 81-84)}

Description. Egg (Fig. 82) long and slender, as long as abdominal segments $3-5$ combined (length $2.2-2.3 \mathrm{~mm}$,
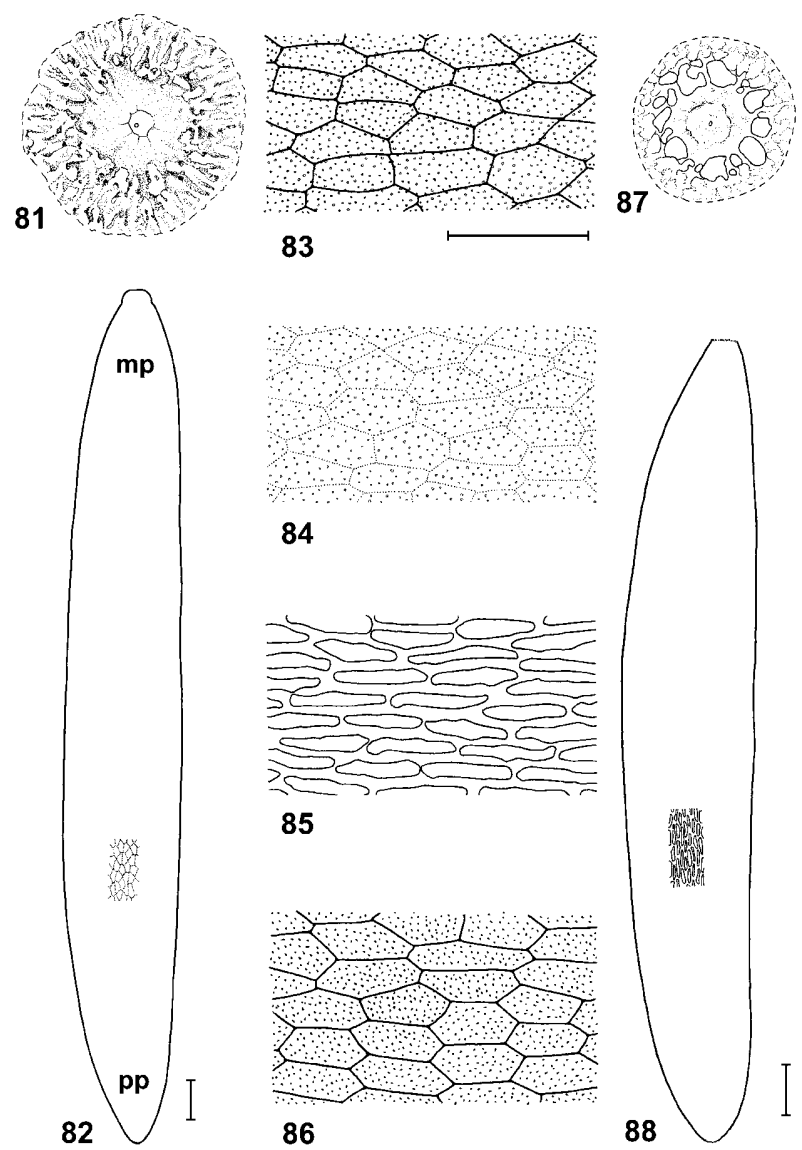

86

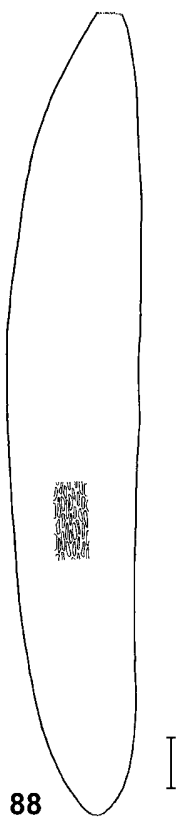

Figs 81-88. Eggs of Loxocera (Imantimyia) achaeta-group. L. (I.) ignyodactyla sp. n. (Costa Rica, Puntarenas): 81 - micropylar area, frontal view; 82 - egg, lateral view; $83,84-$ chorion, lateral surface, fine structure of two different sides. $L$. (I.) ojibwayensis sp. n. (Canada, Ontario): 85 - chorion, dorsal and lateral (?) surfaces, fine structure; 86 - ditto ventral (?) surface; 87 - micropylar area, frontal view; 88 - egg, lateral view. Scale $0.1 \mathrm{~mm}$ (egg, total) and $0.05 \mathrm{~mm}$ (others). $\mathrm{mp}$ - micropylar pole, $\mathrm{pp}$ - posterior pole.

width $0.30-0.33 \mathrm{~mm}$ ), micropylar pole with small truncation, gradually tapered towards rounded posterior pole. Chorion with slightly coarse granular texture, reticulated with somewhat irregular, elongate, linear, polygons, reticulation not elevated. Two opposite sides with distinct reticulation (Fig. 83), elsewhere reticulation practically obliterated and only visible under careful examination (Fig. 84). Micropylar pole (Fig. 81) with "spongy" texture: the mostly medium-sized pores irregular-shaped and not clearly delimited from each other (unlike in the previous species). Posterior pole simple, without pores; granular texture not or hardly coarser than elsewhere.

Material examined. Costa Rica: two eggs from female paratype (full data above).

\section{Discussion}

Morphology. The only previously described Loxocera egg is that of L. aristata (Gaponov, 1999). Gaponov's description diverges radically from the $L$. aristata eggs studied by us, and is obviously based on a different species. His eggs are smaller than any of our species, and are 
in fact only slightly more than half as long as the examined L. aristata eggs from Sweden. Gaponov's SEM micrographs show strong longitudinal ridging connected by small transverse ridges, while our specimens have a completely smooth surface partially covered by linear (not raised), polygonal reticulation. The small size of the eggs and the surface sculpture is consistent with species of the L. fulviventris-group, perhaps pertaining to one of the Palaearctic species L. fulviventris and L. sylvatica. We are also convinced that the two, highly unusual, prominent, circular ridges of the upper surface of the egg described by Gaponov (1999) are due to a preparation artefact. None of the species studied here shows any indication of circular ridging of the egg surface.

Phylogeny. Few characters of phylogenetic significance at the subgenus and species group level were found. Some of the differences that appear to be consistent for certain species groups might turn out to be unreliable when further species from other biogeographic regions are examined. The observed character states are difficult to polarize because eggs of the sister group of Loxocera (Psila s. 1.) and the next outgroup (Chyliza) are very different (see below, and Buck \& Marshall, 2006). The following tentative conclusions can be drawn:

Eggs of the two examined species of Loxocera s. str. are quite different and do not show any obvious synapomorphies. The most striking egg within the subgenus Imantimyia is that of L. albiseta, which possesses a unique micropylar area. This might be considered another autapomorphic character for the L. albiseta-group. Species of the L. fulviventris-group have eggs that are more strongly ridged than in other species and possess very large and uniformly sized pores at the micropylar pole. The latter character is probably apomorphic for the species group. Within the L. achaeta-group the Neotropical L. ignyodactyla sp. $\mathrm{n}$. stands out in egg characters as it does in adult characters. The egg is most significantly characterized by the very weakly sculptured posterior pole. As a whole, the group is difficult to define based on egg morphology. Remarkably, characters like the strength (elevation) of the ridging of the egg surface and the toughness of the chorion vary widely within certain groups, indicating a high degree of homoplasy.

\section{Psila (Asiopsila) decorata (de Meijere, 1914)}

(Figs 89-92)

Description. Egg (Fig. 89) elliptical, ca. $0.65 \times$ as long as abdominal segments 3 and 4 combined (length ca. 0.55 $\mathrm{mm}$, width ca. $0.15 \mathrm{~mm}$ ); micropylar pole with small, circular, disk-like elevation (Fig. 90), posterior pole rounded. Egg surface in mid section with ca. 24 broad, longitudinal, rounded (cross section approximately semicircular) ridges (Fig. 92: clr) around its circumference connected in regular intervals by narrower transverse ridges (Fig. 92: ctr); number of longitudinal ridges decreasing toward poles through anastomoses; at micropylar pole number of ridges equalling number of aeropyles on micropylar elevation; each ridge terminating at an interspace between base of two aeropyles. Both longi-
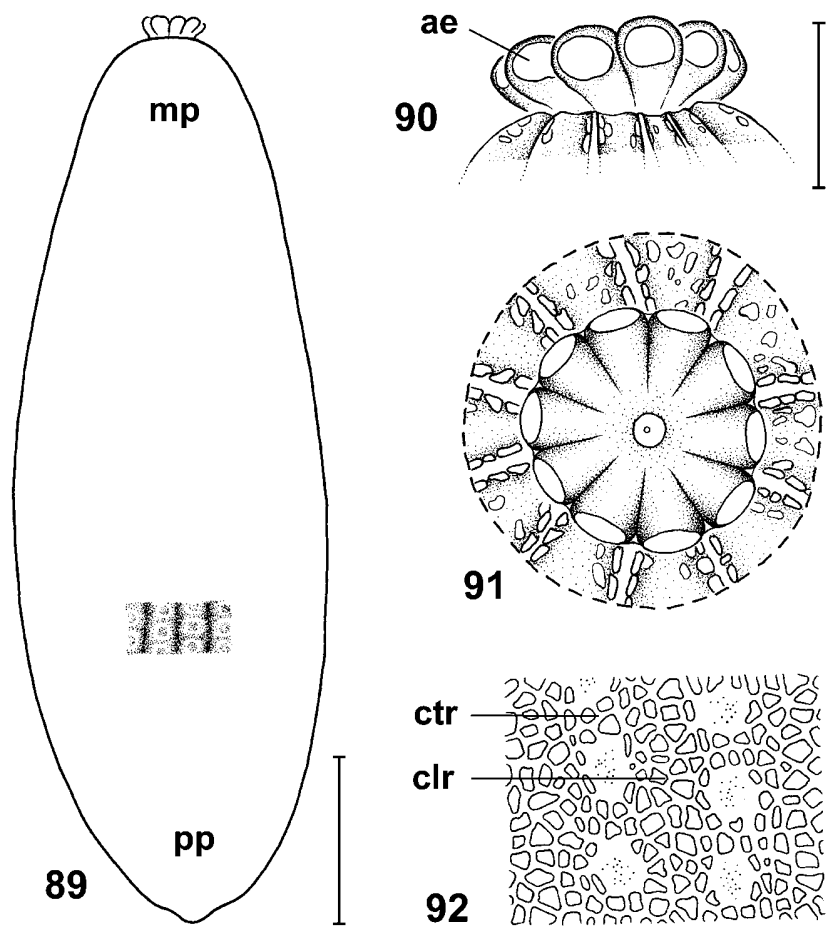

Figs 89-92. Egg of Psila (Asiopsila) decorata (India, Tamil Nadu): 89 - egg, lateral view; 90 - micropylar cap, lateral view; 91 - micropylar cap, frontal view; 92 - chorion, lateral surface, fine structure. Scale $0.1 \mathrm{~mm}$ (egg, total) and $0.025 \mathrm{~mm}$ (others). ae - aeropyle, clr - longitudinal ridge of chorion, ctr - transverse ridge of chorion, $\mathrm{mp}$ - micropylar pole, $\mathrm{pp}$ - posterior pole.

tudinal and transverse ridges with irregular reticulation (reticulation located on inner surface of chorionic air canals; see Hinton, 1981: Plate 123 E, F). Areas between the ridges roughly circular, unreticulated, with small patches of more granular texture. Micropylar elevation (Fig. 91) flat, bearing ten large, circular aeropyles (Fig. 90: ae) around circumference. Micropyle tiny, located exactly in centre of disk-like process. Posterior pole without specialized structures, bearing same reticulation as on longitudinal and transverse ridges.

Material examined. India: 13 eggs from one female, Tamil Nadu, Pulney Hills, Kodaikanal, 6,500 ft, iv.1953, P.S. Nathan (CNCI).

Discussion. The egg of Psila (Asiopsila) decorata is very different from all known Loxocera eggs but is almost identical to eggs of several Psila s. str. species described by Hinton (1981), Gaponov (1999) and Meier \& Hilger (2000) (see also discussion in Buck \& Marshall, 2006).

The most important difference between eggs of Loxocera and Psila is the presence of a peculiar disk-like, micropylar cap with a corona of ca. 9-10 aeropyles in the latter. In Loxocera the micropylar pole is tapered and not developed as a clearly delimited cap; the micropylar aeropyles are distributed in an irregular pattern and are usually much smaller. Apart from the micropylar differences, the longitudinal ridges of the general surface (if present) 
are much more numerous, very narrow (not broad and rounded) and do not possess wide, internally reticulated air canals as in Psila.

The disk-like micropylar cap and wide, reticulated, chorionic air canals of Psila appear to be unique within Psilidae and other Diopsoidea, and clearly define a monophyletic group within the subfamily Psilinae (Buck \& Marshall, 2006). Besides Psila (Asiopsila) and Psila s. str. this group probably includes all the subgenera attributed to Psila s. 1. by recent authors (Shatalkin, 1986, 1989, 2002; Iwasa, 1998).

\section{OUTLOOK}

The present study provides a phylogenetic framework for most of the Holarctic subgenera and species groups of Loxocera. The following topics require further study: (1) Phylogenetic position of Tropeopsila. Critical to solving this question is egg morphology, which will clarify whether this subgenus belongs in Psila s. 1. or Loxocera. (2) Species groups of Loxocera s. str. This Palaearctic/Oriental subgenus was not organized into species groups because only three species were available for examination. Antennal morphology varies widely within the subgenus, and it will be interesting to determine whether external characters are consistent with phylogeny derived from genitalic characters. (3) Relationships of African Loxocera. According to Shatalkin (1998) the African Loxocera species form a monophyletic group. Their subgeneric placement (in Imantimyia or Loxocera s. str.) and relationships with other species groups has yet to be established. (4) Status of Loxocerosoma. The African genus Loxocerosoma was separated from Loxocera on very tenuous grounds (Verbeke, 1968). Its three species probably possess a felt patch on the hind femur and therefore most likely belong in the clade that includes Imantimyia and Loxocera s. str.

ACKNOWLEDGEMENTS. The authors wish to express their thanks to the following colleagues for arranging loans of specimens under their care: J.M. Cumming and J. Skevington (CNCI), Z.H. Falin (SEMC), M. Kotrba (ZSMC), A.L. Norrbom (USNM), M. Zumbado (INBC) and D.C. Currie (ROME). P. Perkins and staff at the MCZC is thanked for providing online digital images of type material of Loxocera housed at their institution. The Instituto Nacional de Biodiversidad (INBio) of Costa Rica is thanked for financially supporting the publication of the colour plates. The illustrations were skilfully executed by M. Musial and A. Cormier (only Fig. 54). This study was funded by NSERC (Natural Sciences and Engineering Research Council of Canada) through different grants to S.A. Marshall.

\section{REFERENCES}

Andersson H. 1977: Taxonomic and phylogenetic studies on Chloropidae (Diptera) with special reference to Old World genera. Entomol. Scand. (Suppl.) 8: 200 pp.

BECKER T. 1905: Cyclorrhapha Schizophora: Holometopa. In Becker T., Bezzi M., Kertész K. \& Stein P. (eds): Katalog der paläarktischen Dipteren, Vol. 4. G. Wesselényi in Hódmezövásárhely, Budapest, 272 pp.

Buck M. (in press): Chapter 61. Psilidae. In Brown B.V., Borkent A., Wood D.M. \& Zumbado M. (eds): Manual of Central American Diptera.
Buck M. \& Marshall S.A. 2006: The identity of Pseudopsila, description of a new subgenus of Psila, and redefinition of Psila sensu lato (Diptera: Psilidae). Eur. J. Entomol. 103: 183-192.

CAPelle K.J. 1953: A revision of the genus Loxocera in North America with a study of geographical variation in L. cylindrica. Ann. Entomol. Soc. Am. 46: 99-114.

Cogan B.H. 1977: Family Psilidae. In Delfinado M.D. \& Hardy D.E. (eds): A Catalog of the Diptera of the Oriental Region. Vol. 3: Suborder Cyclorrhapha (Excluding Division Aschiza). The University Press of Hawaii, Honolulu, pp. 24-27.

Coquillett D.W. 1901: New Diptera in the U.S. National Museum. Proc. U. S. Natn. Mus. 23: 593-618.

FREY R. 1925: Zur Systematik der paläarktischen Psiliden (Dipt.). Notul. Entomol. 5: 47-50.

GAPONOV S.A. 1999: Ultrastructure of egg exochorion in the family Psilidae (Diptera). Zool. Zh. 78: 755-758 [in Russian, English abstr.].

Greve L. \& Skartveit J. 2001: The genus Loxocera (Diptera, Psilidae) in Norway. Norw. J. Entomol. 48: 329-334.

Griffiths G.C.D. 1972: The Phylogenetic Classification of Diptera Cyclorrhapha with Special Reference to the Structure of the Male Postabdomen. Series Entomologica 8, Dr. W. Junk N.V., The Hague, 340 pp.

Hadley A. 2004: CombineZ version 4.6. http://www.microscopy-uk.org.uk/index.html.

Hennig W. 1941: 41. Psilidae. In Lindner E. (ed.): Die Fliegen der Palaearktischen Region. Vol. 5, Lieferung 140, Schweizerbart, Stuttgart, $38 \mathrm{pp}$.

Hinton H.E. 1981: Biology of Insect Eggs. 3 Vols. Pergamon Press, Oxford, xxiv $+1125 \mathrm{pp}$.

IWASA M. 1992: Notes on the genus Loxocera Meigen (Diptera, Psilidae) from Japan, Sakhalin and the Kuril Islands. Jap. J. Entomol. 60: 229-237.

IwASA M. 1993: The genus Loxocera Meigen (Diptera, Psilidae) from Nepal, with descriptions of two new species. Jap. J. Entomol. 61: 243-249.

IwASA M. 1996: Two new species of the genus Loxocera Meigen (Diptera, Psilidae) from China and Sri Lanka. Jap. J. Entomol. 64: 61-66.

IwaSA M. 1998: 3.11. Family Psilidae. In Papp L. \& Darvas B. (eds): Contributions to a Manual of Palaearctic Diptera (with Special Reference to Flies of Economic Importance). Vol. 3: Higher Brachycera. Science Herald, Budapest, pp. 177-183.

JoHNSON C.W. 1920: A revision of the species of the genus Loxocera, with a description of a new allied genus and a new species. Psyche (Camb.) 27: 15-19.

LoEw H. 1869: Diptera Americae septentrionalis indigena. Berl. Entomol. Z. 13: 1-52, 129-186.

Macquart J. 1835: Histoire Naturelle des Insectes. Diptères. Vol. 2. Paris, iv +703 pp.

McAlpine J.F. 1981: Morphology and terminology - adults. In McAlpine J.F., Peterson B.V., Shewell G.E., Teskey H.J., Vockeroth J.R. \& Wood D.M. (eds): Manual of Nearctic Diptera. Vol. 1. Research Branch, Agriculture Canada, Monograph 27, Ottawa, pp. 9-63.

Meier R. \& Hilger S. 2000: On the egg morphology and phylogenetic relationships of Diopsidae (Diptera: Schizophora). $J$. Zool. Syst. Evol. Res. 38: 1-36.

MeIGen J.W. 1803: Versuch einer neuen GattungsEintheilung der europäischen zweiflügligen Insekten. Mag. Insektenk. 2: 259-281.

MeIgen J.W. 1826: Systematische Beschreibung der bekannten europäischen zweiflügligen Insekten, Vol. 5. Schulzische Buchhandlung, Hamm, xii + 412 pp. 
DE MeIJere J.C.H. 1941: Pupariën van Loxocera in stengels van Juncus. Entomol. Ber. (Amst.) 10: 286-287.

DE MeIJere J.C.H. 1945: Over eenige Dipterenlarven, waaronder een galmug, die mijngangen makt, en twee Dipteren, die gallen op paddenstoelen veroorzaken. Tijdschr. Entomol. 88: 49-62.

Melander A.L. 1920: Synopsis of the dipterous family Psilidae. Psyche (Camb.) 27: 91-101.

Panzer G.W.F. 1801: Faunae insectorum germanicae initiae oder Deutschlands Insekten Fasc. 73. Nürnberg, 24 pp.

SAY T. 1823: Descriptions of dipterous insects of the United States. J. Acad. Nat. Sci. Philad. 3: 9-54, 73-104.

SCHRANK F. VON P. 1803: Fauna Boica. Durchgedachte Geschichte der in Baiern einheimischen und zahmen Tiere, Vol. 3(1). Landshut, 272 pp.

Shatalkin A.I. 1983: New species of flies of the family Psilidae (Diptera) from the Far East. Entomol. Obozr. 62: 360-366 [in Russian; English translation in Entomol. Rev., Wash. 62: 127-134].

Shatalkin A.I. 1986: Review of the eastpalaearctic flies of Psila Mg. (Diptera, Psilidae), with the key of the Palaearctic species. Proc. Zool. Inst., Leningrad 146: 23-43 [in Russian, English abstr.].

Shatalkin A.I. 1989: Notes on the Palaearctic Psilidae (Diptera). Archs Zool. Mus. Moscow State Univ. 27: 88-113 [in Russian, English abstr.].

Shatalkin A.I. 1998: Asian species of Loxocera Meigen (Diptera: Psilidae). Russ. Entomol. J. 6(3-4) [1997]: 87-97.

Shatalkin A.I. 2002: Afrotropical Psilidae (Diptera). 1. Genera Belobackenbardia gen. n. and Psila Meigen, 1803. Russ. Entomol. J. 10 [2001]: 417-424.
Shewell G.E. 1965: Family Psilidae. In Stone A., Sabrosky C.W., Wirth W.W., Foote R.H. \& Coulson J.R. (eds): $A$ Catalog of the Diptera of America North of Mexico. United States Department of Agriculture, Washington, D.C., pp. 638-641.

Soós A. 1984: Family Psilidae. In Soós A. \& Papp L. (eds): Catalogue of Palaearctic Diptera. Vol. 9. Akadémiai Kiadó, Budapest, pp. 28-35.

Steyskal G.C. 1987: 60. Psilidae. In McAlpine J.F., Peterson B.V., Shewell G.E., Teskey H.J., Vockeroth J.R. \& Wood D.M. (eds): Manual of Nearctic Diptera. Vol. 2. Research Branch, Agriculture Canada, Monograph 28, Ottawa, pp. 781-784.

Valley K., Wearsch T. \& Foote B.A. 1969: Larval feeding habits of certain Chloropidae (Diptera). Proc. Entomol. Soc. Wash. 71: 29-34.

Verbeke J. 1952: Psilidae (Diptera Cyclorrhapha). Explor. Parc Natn Albert, Miss. G.F. de Witte, 1933-1935, 78: 64 pp.

Verbeke J. 1968: Psilidae (Diptera Acalyptera). Explor. Parc Natn Garamba, Miss. H. de Saeger 53: 65-78.

WANG X. 1988: Bestimmungstabelle der westpaläarktischen Chamaepsila-Arten (Diptera: Psilidae). Stuttg. Beitr. Naturk. (A) 417: $13 \mathrm{pp}$.

Wang X. \& Yang Ch. 1996: Psilidae. In Xue W. \& Chao Ch. (eds): Flies of China. Vol. 1. Liaoning Science and Technology Press, Shenyang, pp. 424-456 [in Chinese, English diagnoses for newly described taxa].

Received March 23, 2005; revised and accepted September 21, 2005 